Characterization of High Level Waste from a Hybrid LIFE Engine for Enhanced Repository Performance

E. Beckett, M. Fratoni

September 20, 2010 
This document was prepared as an account of work sponsored by an agency of the United States government. Neither the United States government nor Lawrence Livermore National Security, LLC, nor any of their employees makes any warranty, expressed or implied, or assumes any legal liability or responsibility for the accuracy, completeness, or usefulness of any information, apparatus, product, or process disclosed, or represents that its use would not infringe privately owned rights. Reference herein to any specific commercial product, process, or service by trade name, trademark, manufacturer, or otherwise does not necessarily constitute or imply its endorsement, recommendation, or favoring by the United States government or Lawrence Livermore National Security, LLC. The views and opinions of authors expressed herein do not necessarily state or reflect those of the United States government or Lawrence Livermore National Security, LLC, and shall not be used for advertising or product endorsement purposes.

This work performed under the auspices of the U.S. Department of Energy by Lawrence Livermore National Laboratory under Contract DE-AC52-07NA27344. 


\section{Characterization of High Level Waste from a Hybrid LIFE Engine for Enhanced Repository Performance}

\section{Elizabeth Beckett}

Mentor: Massimiliano Fratoni

This work performed under the auspices of the U.S. Department of Energy by Lawrence Livermore National Laboratory under Contract DE-AC52-07NA27344. 


\section{Contents}

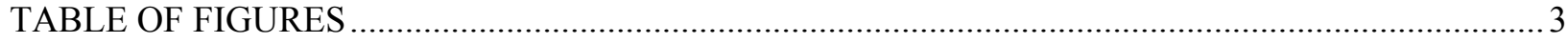

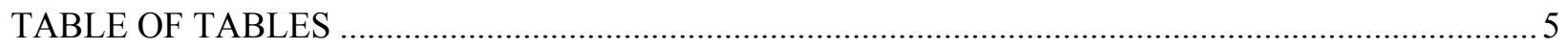

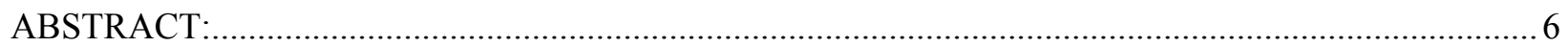

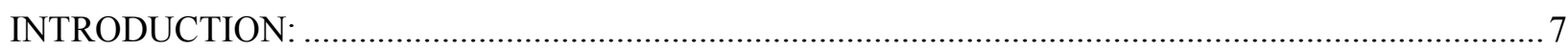

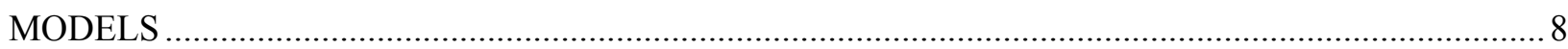

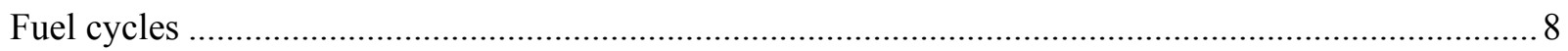

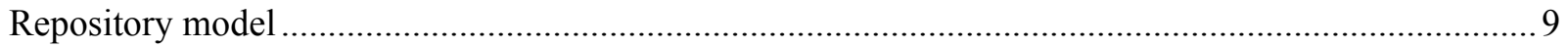

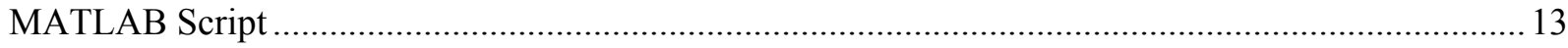

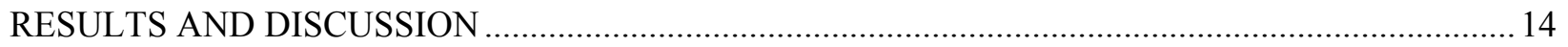

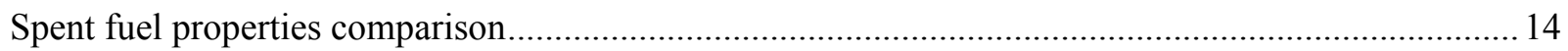

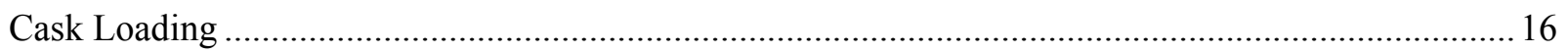

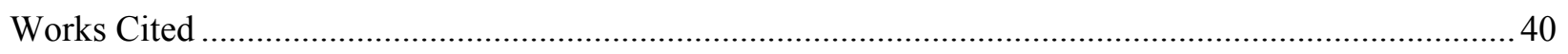

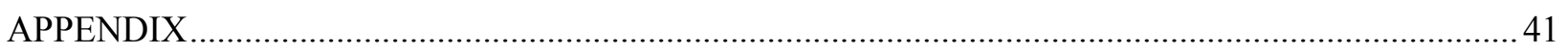

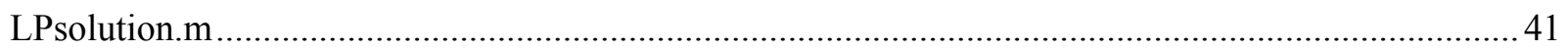

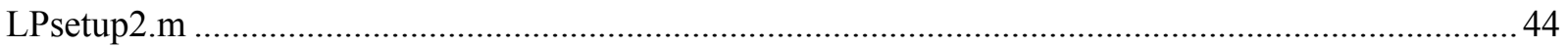

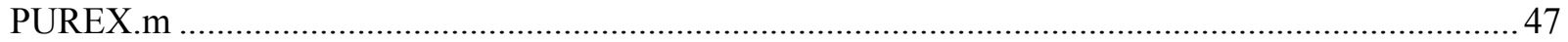




\section{TABLE OF FIGURES}

Figure 1: Fuel cycle for LIFE with LWR recovered fuel................................................................ 10

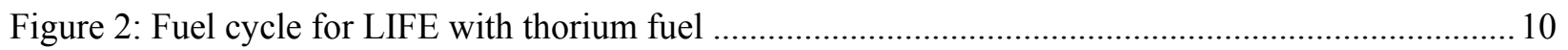

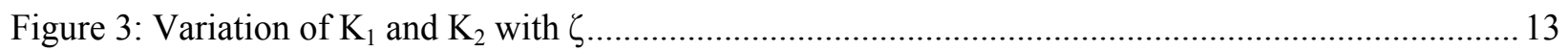

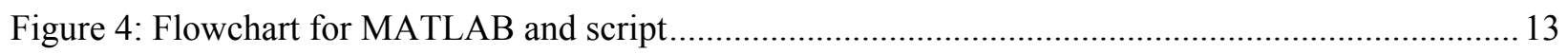

Figure 5: Activity variation for LIFE fueled with either AIROX reprocessed fuel or thorium compared to a traditional $50 \mathrm{GWd} / \mathrm{tHM}$ PWR (normalized per tHM) ................................................................. 18

Figure 6: Activity variation for LIFE fueled with either AIROX reprocessed fuel or thorium compared to

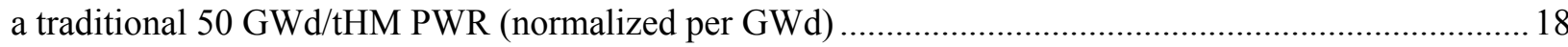

Figure 7: Decay heat variation for LIFE fueled with either AIROX reprocessed fuel or thorium compared

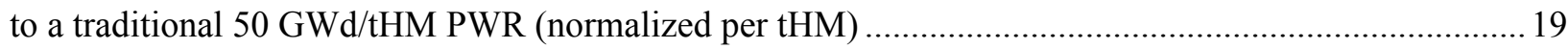

Figure 8: Decay heat variation for LIFE fueled with either AIROX reprocessed fuel or thorium compared to a traditional $50 \mathrm{GWd} /$ tHM PWR (normalized per GWd) .............................................................. 19

Figure 9: Inhalation hazard variation for LIFE fueled with either AIROX reprocessed fuel or thorium compared to a traditional $50 \mathrm{GWd}$ /tHM PWR (normalized per tHM) .................................................220 Figure 10: Inhalation hazard variation for LIFE fueled with either AIROX reprocessed fuel or thorium compared to a traditional $50 \mathrm{GWd}$ /tHM PWR (normalized per GWd) ................................................ 20 Figure 11: Ingestion hazard variation for LIFE fueled with either AIROX reprocessed fuel or thorium compared to a traditional $50 \mathrm{GWd}$ /tHM PWR (normalized per tHM)

Figure 12: Ingestion hazard variation for LIFE fueled with either AIROX reprocessed fuel or thorium compared to a traditional $50 \mathrm{GWd}$ /tHM PWR (normalized per GWd) ................................................2 21 Figure 13: Np237 and precursor levels for LIFE fueled with either AIROX reprocessed fuel or thorium compared to a traditional $50 \mathrm{GWd}$ /tHM PWR (normalized per GWd) ..................................................2 22 Figure 14: Np237 and precursors for LIFE fueled with either AIROX reprocessed fuel or thorium compared to a traditional $50 \mathrm{GWd} / \mathrm{tHM}$ PWR (normalized per GWd) 22

Figure 15: Total neutron source for LIFE fueled with either AIROX reprocessed fuel or thorium compared to a traditional $50 \mathrm{GWd}$ /tHM PWR (normalized per tHM) .23

Figure 16: Total neutron source for LIFE fueled with either AIROX reprocessed fuel or thorium compared to a traditional $50 \mathrm{GWd} / \mathrm{tHM}$ PWR (normalized per GWd)

Figure 17: Fission product mass for LIFE fueled with either AIROX reprocessed fuel or thorium compared to a traditional $50 \mathrm{GWd} / \mathrm{tHM}$ PWR (normalized per tHM)

Figure 18: Fission product mass for LIFE fueled with either AIROX reprocessed fuel or thorium compared to a traditional $50 \mathrm{GWd} / \mathrm{tHM}$ PWR (normalized per GWd) ...

Figure 19: TRU mass for LIFE fueled with either AIROX reprocessed fuel or thorium compared to a traditional $50 \mathrm{GWd} / \mathrm{tHM}$ PWR (normalized per tHM). 25

Figure 20: TRU mass for LIFE fueled with either AIROX reprocessed fuel or thorium compared to a traditional $50 \mathrm{GWd} / \mathrm{tHM}$ PWR (normalized per GWd).

Figure 21: Fissile mass for LIFE fueled with either AIROX reprocessed fuel or thorium compared to a traditional $50 \mathrm{GWd} / \mathrm{tHM}$ PWR (normalized per tHM)... 26 Figure 22: Fissile mass for LIFE fueled with either AIROX reprocessed fuel or thorium compared to a traditional $50 \mathrm{GWd} / \mathrm{tHM}$ PWR (normalized per GWd)...... .26 Figure 23: Fissile fraction for LIFE fueled with either AIROX reprocessed fuel or thorium compared to a traditional $50 \mathrm{GWd} / \mathrm{tHM}$ PWR. 27 
Figure 24: Plutonium fraction for LIFE fueled with either AIROX reprocessed fuel or thorium compared to a traditional $50 \mathrm{GWd} / \mathrm{tHM}$ PWR 27

Figure 25: $28 \mathrm{GWd} / \mathrm{tHM}$ metal burnup, $4.0 \mathrm{wt} \%{ }^{235} \mathrm{U}$ benchmark solution for PWR ..............................2 29

Figure 26: $28 \mathrm{GWd} / \mathrm{tHM}$ metal burnup, $4.0 \mathrm{wt} \%{ }^{235} \mathrm{U}$ benchmark solution for PWR from Ahn ..............29

Figure 27: Feasibility Solution for BU $=90 \%$ FIMA and cooling of 5 years for LIFE with thorium fuel

(THOREX not used). 30

Figure 28: Feasibility Solution for BU $=80 \%$ FIMA and cooling of 20 years for LIFE fueled with used

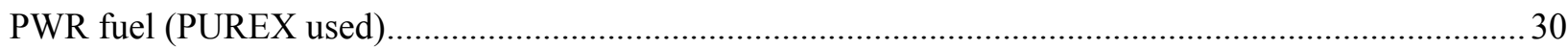

Figure 29: Total HLW waste generated per initial tHM (decay time of five years) ................................. 32

Figure 30: Total HLW generated per GWd (decay time of five years) .................................................. 32

Figure 31: Fraction of canister needed to store HLW per initial tHM (decay time of five years) .............. 32

Figure 32: Fraction of canister needed to store HLW from a GWd (decay time of five years).................. 33

Figure 33: Minimum cooling time required for cask loading independent of decay heat ......................... 33

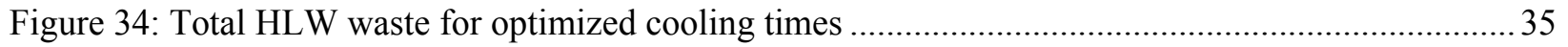

Figure 35: Total HLW (per GWd) for optimized cooling time ............................................................ 35

Figure 36: Number of canisters (per tHM) for optimized cooling time.................................................. 35

Figure 37: Number of canisters (per GWd) for optimized cooling time ................................................ 36

Figure 38: Increased energy production per canister after optimized cooling time ................................... 36 


\section{TABLE OF TABLES}

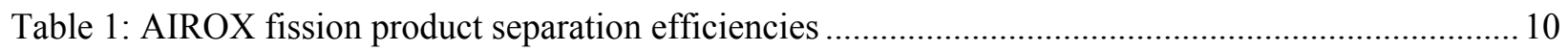

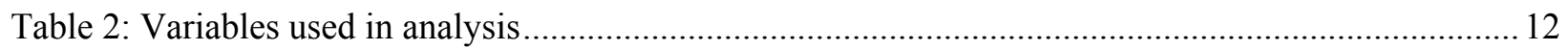

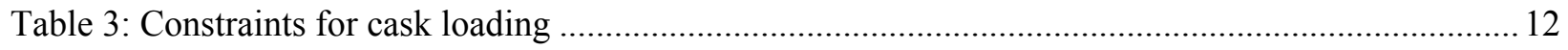

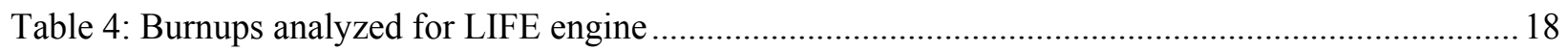

Table 5: Rank of various parameters related to repository performance …............................................28

Table 6: Key statistics for cask loading. The optimal solution of mass of HLW and glass in the container are give, as well as the number of canisters required for loading, normalized per tHM and per GWd.

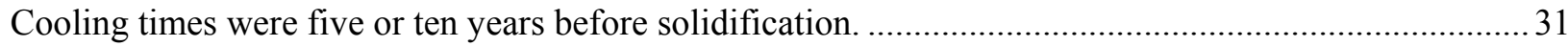

Table 7: Key statistics for cask loading with optimized cooling times. The optimal solution of mass of HLW and glass in the container are give, as well as the number of canisters required for loading,

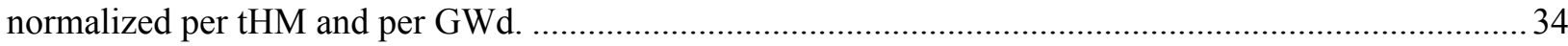

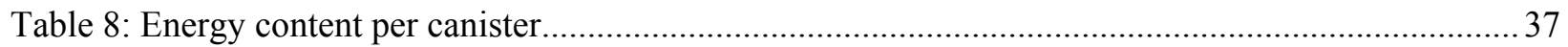




\begin{abstract}
:
In the interest of providing unlimited greenhouse gas-free energy at low cost, the Laser Inertial Fusion Energy (LIFE) project provides a testbed for inertial confinement fusion technology. Proposed designs are a pure fusion reactor or a hybrid fusion-fission reactor, which includes a subcritical blanket of fissionable material to be irradiated by neutrons from the fusion reaction. Two possible fuels are considered: (1) used fuel from current reactors; (2) thorium. Amounts of high level waste (HLW) generated per kilowatt-hour $\left(\mathrm{kW}^{*} \mathrm{~h}\right)$ produced are lower relative to current Light Water Reactors (LWR), but potential hazard associated with 1 ton of HLW from LIFE is superior. The scope of this study is to combine quantities and qualities of HLW from LIFE and determine the repository space required relative to HLW from LWR for a once through fuel cycle. Repository space was determined in terms of number of canisters required disposal of waste in the production of $1 \mathrm{~kW}^{*} \mathrm{~h}$. HLW properties were determined using the Oak Ridge Isotope GENeration code (ORIGEN-S) and waste was conditioned and stored in borosilicate glass. For a LWR, the fuel was burnt to 50 gigawatt-days per tonne heavy metal $(\mathrm{GWd} / \mathrm{tHM})$ then reprocessed through Plutonium Uranium Extraction (PUREX). For LIFE, fuel burnup varied from 478.6 to $971.8 \mathrm{GWd} / \mathrm{tHM}$ and both PUREX reprocessing and conditioning with no separation were analyzed. HLW load per canister was determined for each fuel by combining mass, decay heat, and composition constraints, but the decay heat constraint was eliminated, allowing the spent fuel to cool before solidification. If PUREX reprocessing is applied, LIFE requires $1.47 \mathrm{E}-10$ and $1.39 \mathrm{E}-10$ canisters per $\mathrm{kW}^{*} \mathrm{~h}$ for used fuel and thorium fuel, respectively. A LWR requires $1.56 \mathrm{E}-10$ canisters per $\mathrm{kW}^{*} \mathrm{~h}$. Limiting constraints for LIFE spent fuel were mass of the canister, mass fraction of the glass frit, or molybdenum trioxide mass fraction. If uranium and plutonium are not separated from LIFE spent fuel, then 2.10E-10 and 1.96E-10 canisters are required per $\mathrm{kW}^{*} \mathrm{~h}$, for the used fuel and thorium fuel, respectively. Required number of canisters decreases with increased fuel burnup. HLW waste disposal of LIFE is not only feasible, but more efficient than LWR with separation per $\mathrm{kW}^{*} \mathrm{~h}$. High burnups of LIFE offer the greatest waste performance benefit. Limitations of the study include assumption of generic processing or PUREX extraction for LIFE fuel. Future work will include environmental impact after canister failure.
\end{abstract}




\section{INTRODUCTION:}

The purpose of this analysis is to find the volume of high level waste (HLW) generated in a fuel cycle that include LIFE (Laser Inertial Fusion-based Energy) engines as compared to a LWR (Light Water Reactor) once-through fuel cycle. For the LIFE system, two options are considered: (1) LIFE is used to burn used fuel from LWR recovered through the AIROX process; (2) LIFE is fueled with thorium only. The volume of waste requiring deep geological disposal is determined in number of canisters. Additionally, a parametric analysis was performed in order to characterize the HLW waste being stored in the canisters. The report will first detail models used in the analysis, which include details for the repository and fuel cycles analyzed. Calculation methods will be detailed, including specific calculations performed and scripting tools used. Next, results of the parametric analysis and the cask loading results will be given and discussed. Finally, overall conclusions for both facets of the study will be given. 


\section{MODELS}

Fuel cycles

LIFE fueled with recovered used LWR Fuel

Figure 1 shows the fuel cycle for a LIFE engine fed with used fuel form LWR. LWR fuel was burned through three cycles to $50 \mathrm{GWd} / \mathrm{tHM}$. Enrichment was $5.0 \mathrm{wt} \% \mathrm{U}-235$. After a cooling time of twenty years, the fuel is recovered via the AIROX process and refabricated. Only volatile and partially semi-volatile fission products are extracted from the used fuel (Table 1). Elements removed are primary noble gasses, but also include cesium, tellurium, ruthenium, cadmium, and iridium. Next, this refabricated fuel was burned in LIFE. Simultaneously, the fission products removed via AIROX were depleted via the Origen-S code for 40 years. These same fission products were added back into the end-of-cycle waste from LIFE. The simplification made was that LIFE would run for 40 years, regardless of burnup, and the AIROX-removed fission products would decay simultaneously. The spent fuel from LIFE was let decay before vitrification and disposal. Two different options were assumed for the conditioning phase. The first option assumed that there was no reprocessing, and the fuel was simply mechanically separated from the carbon. In the second, it was assumed that the LIFE spent fuel underwent PUREX reprocessing.

\section{LIFE fueled with thorium}

Figure II details the thorium fuel cycle, which is simpler than the extended LWR-LIFE fuel cycle previously described in Figure 1. The thorium fuel cycle simply assumes that a LIFE engine converts thorium to ${ }^{233} \mathrm{U}$ and burns this directly, in a single pass mode. The spent fuel after cooling is either disposed in its original composition or reprocessed through THOREX.

\section{LWR fuel cycle}

For LWR reactor a once-through fuel cycle was assumed. The initial fuel is enriched 5.0 wt $\%$ in ${ }^{235} \mathrm{U}$ and is burned through for three cycles to $50 \mathrm{GWd} / \mathrm{tHM}$. After cooling and before disposal the spent fuel is reprocessed through PUREX.

For all fuel cycles the cooling time before disposal was assumed to be a parameter, varying from 5 to 40 years. For the PUREX process, uranium and plutonium are separated out with $0.604 \%$ and $0.2966 \%$ remaining in the waste stream, and all noble gasses are separated out completely. THOREX is still an experimental process, but for the purposes of this study, uranium, plutonium, and thorium are extracted similarly to PUREX with $0.604 \%, 0.2966 \%$ respectively, and $0.700 \%$ remaining in the waste stream, respectively. The value for thorium efficiency was chosen by the author to insure conservatism.

The high level waste arising from each of these fuel cycles is assumed to be disposed in the form of borosilicate glass. This process is currently used to vitrify defense HLW from the weapons complex. Borosilicate glass consists of boron oxide and silica. The boron serves as a neutron absorber. (Saling \& Fentiman, 2001) 


\section{Repository model}

This study assumes the repository has the characteristics of the proposed Yucca Mountain repository. Assumptions and constraints are based off of the federal regulations relevant to this repository. Each canister is modeled as a cylinder with outer cladding, with vitrified HLW distributed homogeneously. Principal decay heat emitters are also homogeneously distributed with the canister. All released decay heat is absorbed in the borosilicate glass. In interim storage, the canisters are stacked on top of each other. Canisters are cooled naturally by air. The maximum temperature is on the centerline of the canisters, and heat conduction in the axial direction is neglected, in order to insure conservatism. Steady state heat transfer at time of emplacement with constant heat emission rate is assumed and radiation effects are ignored. LIFE with used LWR fuel and PWR undergo the same conditioning and vitrification: either PUREX or reprocessing without actinide extraction. LIFE with thorium fuel is assumed to undergo either THOREX reprocessing, or reprocessing without actinide (including thorium) extraction. For simplicity, it is assumed that process and corrosion chemicals are proportional to the amount of waste processed, and are the same for both PUREX and THOREX. 


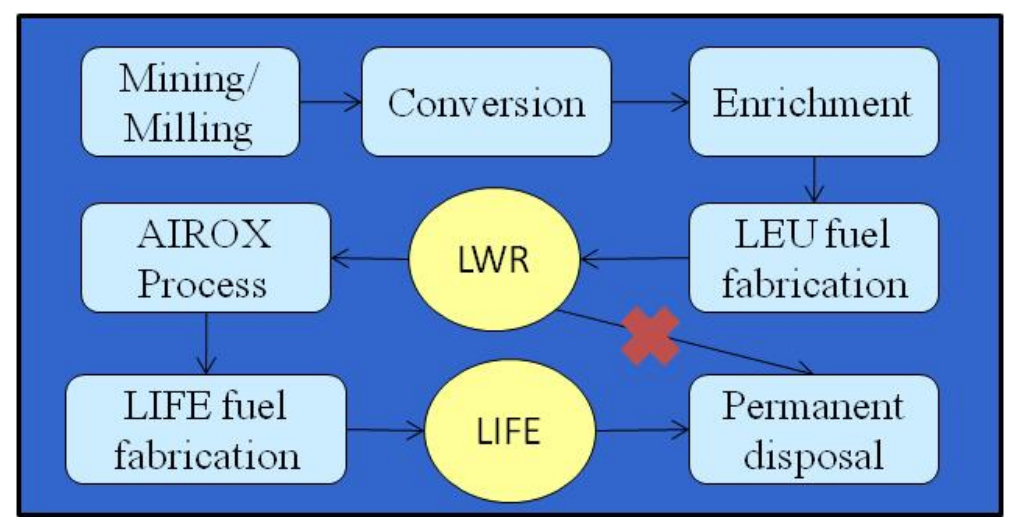

Figure 1: Fuel cycle for LIFE with $L W R$ recovered fuel

Table 1: AIROX fission product separation efficiencies

\begin{tabular}{|c|c|}
\hline Element & $\begin{array}{c}\text { Separation } \\
\text { efficiency }(\%)\end{array}$ \\
\hline $\mathrm{H}$ & 100 \\
\hline $\mathrm{Kr}$ & 100 \\
\hline $\mathrm{Ru}$ & 100 \\
\hline $\mathrm{Cd}$ & 75 \\
\hline $\mathrm{Te}$ & 75 \\
\hline Ir & 75 \\
\hline $\mathrm{I}$ & 100 \\
\hline $\mathrm{Xe}$ & 100 \\
\hline $\mathrm{Cs}$ & 100 \\
\hline Other & 0 \\
\hline
\end{tabular}

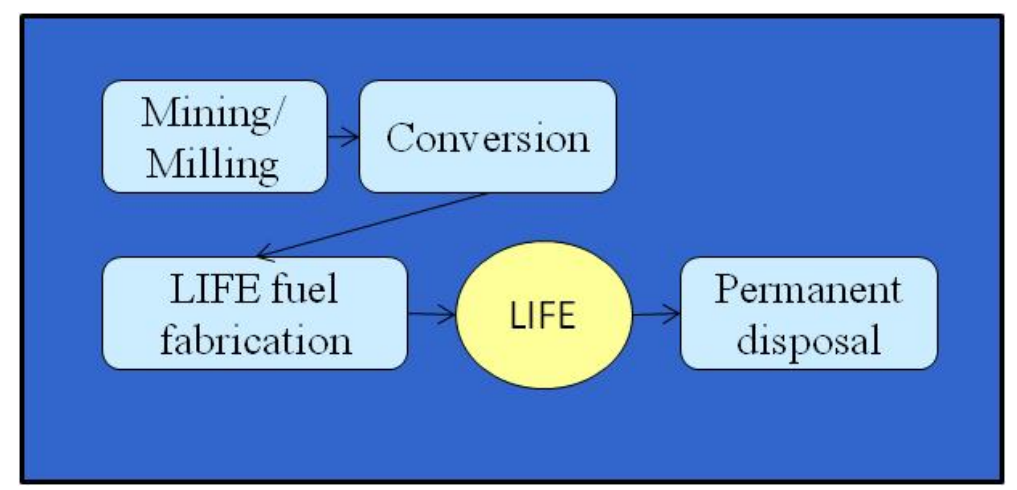

Figure 2: Fuel cycle for LIFE with thorium fuel 


\section{METHODOLOGY}

In order to determine the volume of HLW waste generated in each of the fuel cycle multiple steps are necessary: (1) fuel depletion in the reactor; (2) spent fuel cooling; (3) reprocessing; (4) condition and vitrification.

For this study, the composition of the spent fuel discharged from a LIFE engine was provided (Fratoni, 2010) (Powers, 2010), whereas composition from the PWR was determined using the Origen-S code. (Gauld, 2009) Spent fuel cooling was also modeled with Origen-S for both systems.

Reprocessing, vitrification, and canister loading were computed with a newly designed MATLAB script. After the optional PUREX or THOREX reprocessing, the borosilicate glass composition, that includes processing and corrosion chemicals besides the spent fuel, was determined. For the case where the fuel is simply recovered without any actinide separation, it was assumed that amounts of chemicals were identical to those used in the vitrification during PUREX for PWR fuel. These are linearly proportional to the amount of waste being vitrified. Finally, the amount of high level waste that can be loaded in a canister was determined according to mass, volume, material, and waste composition constraints. Seven constraints were modeled. Variable descriptions are given in Table 2 and the linearized form is given in Table 3.

These constraints are based upon federal regulation. The first three constraints are independent of the HLW composition. The first constraint limits the canister mass to $2500 \mathrm{~kg}$. The second constraint requires that the volume of vitrified HLW must be between $80 \%$ and $100 \%$ of the volume of the canister. The third constraint limits the mass fraction of glass frit to be between $70 \%$ and $85 \%$ of the vitrified waste. The fourth constraint imposes that the temperature of the canister cannot exceed $400^{\circ} \mathrm{C}$ in the vitrified waste. The derived linear relationship between temperature and heat emission can be interpolated from Figure 3, and constants $\mathrm{K}_{1}$ and $\mathrm{K}_{2}$ can be used to graph the resulting constraint. The coefficients $\mathrm{K}_{1}$ and $\mathrm{K}_{2}$ are equally valid for both LIFE and PWR fuel, as they are approximation from the thermal hydraulics of the canister and the total heat emission of the canister, and not dependent of the composition of the nuclides in the waste producing heat emission. The fifth constraint prescribes that the concentration of plutonium must be less than $2.5 \mathrm{~kg} / \mathrm{m}^{3}$. The sixth constraint is that the amount of molybdenum trioxide cannot exceed $2 \mathrm{wt} \%$ of the vitrified HLW. The seventh and final constraint is that the amount of sodium dioxide content cannot exceed $10 \mathrm{wt} \%$ of vitrified HLW. All constraints will apply equally to LIFE or LWR fuel, since the assumption is made that the conditioning chemicals used are the same.

The combination of all the constraints determines the number of canister necessary for each fuel cycle. These constraints are combined using linear programming techniques, meaning they were linearized (if needed) and graphed to form a feasible solution space. These provide a space of feasible solutions given by combinations of HLW mass and glass mass. Assuming that the scope is to minimize the repository space, the preferred solution among the feasible combinations is the one that minimize the number of canisters, i.e. maximize the HLW waste load per canister. Analysis was normalized pet tHM and per GWd to facilitate comparison.

A MATLAB script was used to input composition data and calculate these variables and constraints, as well as to apply processing to the input composition. Additionally, it performed necessary normalizations for relevant data. A copy of the MATLAB script is given in the appendix. 
Table 2: Variables used in analysis

\begin{tabular}{|c|l|}
\hline \multicolumn{1}{l|}{ Variable } & Description \\
\hline$M_{G}$ & Mass of glass frit \\
\hline$M_{W}$ & Constants used to calculate heat flux linearization \\
\hline$K_{1}, K_{2}$ & Heat emission rate per unit mass of HLW waste \\
\hline$\zeta$ & Volume of canister $\left(.823 \mathrm{~m}^{3}\right)$ \\
\hline$V_{C}$ & Weight fraction of plutonium \\
\hline$x_{W, P U}$ & Weight fraction of molybdenum trioxide \\
\hline$x_{\mathrm{MOO} 3}$ & Weight fraction of sodium dioxide \\
\hline$x_{W, N a O_{2}}$ & Weight fraction of sodium dioxide in glass frit (assumed to be 0$)$ \\
\hline$x_{G, N a O_{2}}$ &
\end{tabular}

Table 3: Constraints for cask loading

\begin{tabular}{|c|c|c|}
\hline \multicolumn{3}{|c|}{ Constraints for Cask Loading } \\
\hline 1 & $\begin{array}{l}\text { Total mass of the waste container } \\
\text { must be less than } 2500 \mathrm{~kg}\end{array}$ & $2033-M_{G} \leq M_{W}$ \\
\hline 2 & $\begin{array}{l}\text { The volume of the vitrified } \\
\text { HLW must be between } 80 \text { and } \\
100 \% \text { of the canister volume }\end{array}$ & $\begin{array}{rl}2393.7-1.505 & * M_{G} \leq M_{W} \\
& \leq 2932.3-1.505 * M_{G}\end{array}$ \\
\hline 3 & $\begin{array}{l}\text { The mass fraction of } \\
\text { the glass frit must be between } 70 \\
\text { and } 85 \%\end{array}$ & $0.1765 * M_{G} \leq M_{W} \leq 0.4286 * M_{G}$ \\
\hline 4 & $\begin{array}{l}\text { The highest temperature in } \\
\text { vitrified } \mathrm{HLW} \text { must be } 400^{\circ} \mathrm{C} \text {. }\end{array}$ & $M_{G} * K_{1}+K_{2} \leq M_{W}$ \\
\hline 5 & $\begin{array}{l}\text { The concentration of plutonium } \\
\text { in vitrified HLW must be less than } \\
2.5 \mathrm{~kg} / \mathrm{m}^{3}\end{array}$ & $2.5 * \frac{V_{c}}{x_{W P U}} * M_{G} \leq M_{W}$ \\
\hline 6 & $\begin{array}{l}\text { The mass fraction of molybdenum } \\
\text { trioxide in vitrified HLW must be } \\
\text { less than } 2 \mathrm{wt} \%\end{array}$ & $\left(\frac{0.02}{x_{\mathrm{MoO}_{3}}-.02}\right) * M_{G} \leq M_{W}$ \\
\hline 7 & $\begin{array}{l}\text { The upper bound for the mass } \\
\text { fraction of sodium dioxide in } \\
\text { vitrified HLW is } 10 \%\end{array}$ & $\frac{.1-x_{G N a_{2} 0}}{x_{W N a 20}-.1} * M_{G} \leq \mathrm{M}_{W}$ \\
\hline
\end{tabular}




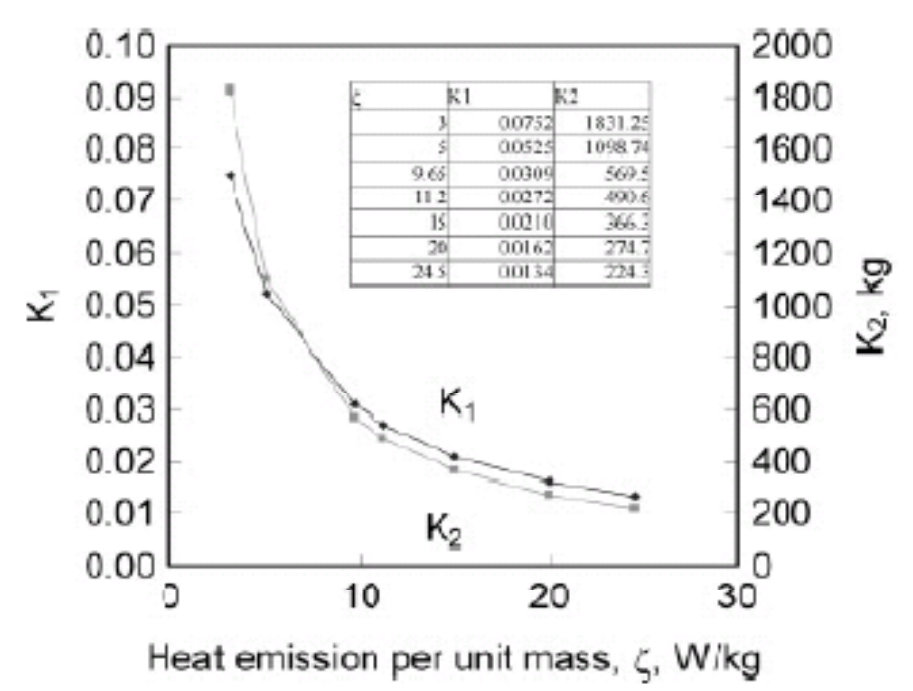

Fig. 5. Variations of coefficients $K_{1}$ and $K_{2}$ with $\zeta$.

Figure 3: Variation of $K_{1}$ and $K_{2}$ with $\zeta$

\section{MATLAB Script}

Inputs to the script from Origen-S were formatted in a Microsoft Excel file. The MATLAB script asked the user for the burnup to be analyzed, input the data, and offered PUREX and THOREX options with extraction. The script then found the parameters needed to graph the constraint equations. Outputs from the script were a graph of the feasibility solution as well as total HLW and number of canisters needed. These values were normalized per GWd and per tHM. A flow chart is given below in Figure 4. The input code for the thorium fuel is given in the appendix.

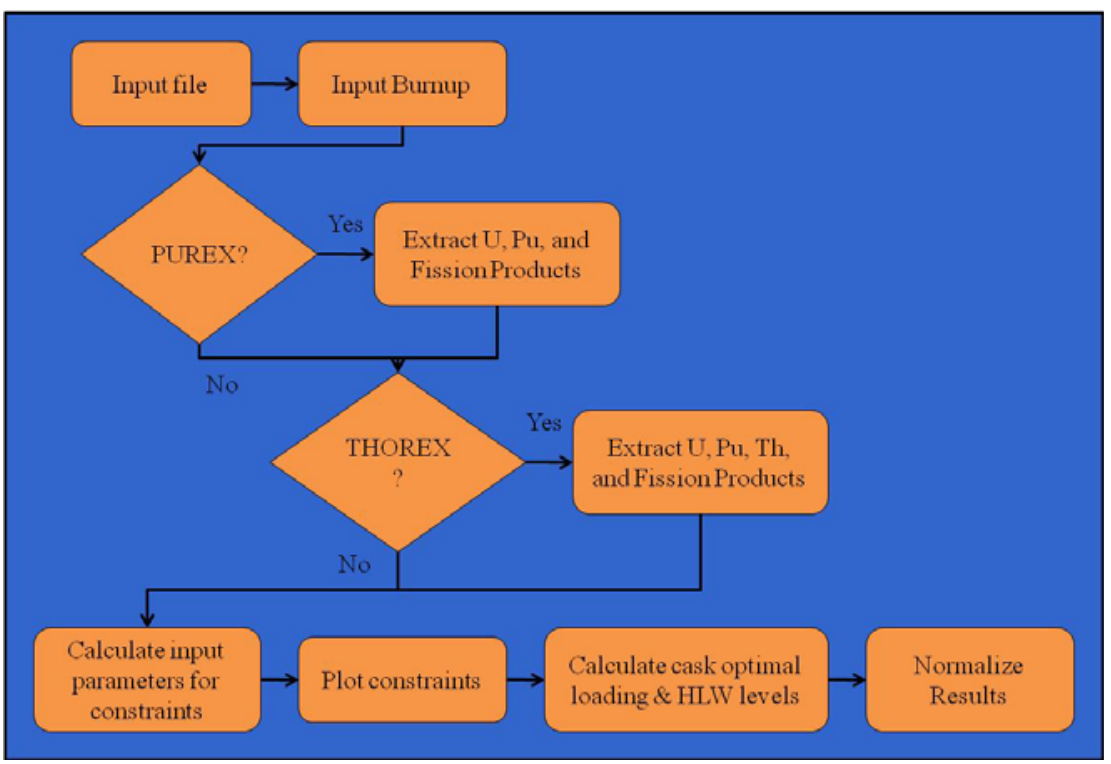

Figure 4: Flowchart for MATLAB and script 


\section{RESULTS AND DISCUSSION}

\section{Spent fuel properties comparison}

The properties of the spent fuel as discharged from the reactor, either LIFE or LWR, were analyzed in order to identify the fuel cycle specific characteristics. Activity levels, decay heat, radiotoxicity (both inhalation and ingestion hazards), Neptunium-237 and precursor levels, total neutron source levels, product mass, transuranic (TRU) mass, fissile mass, fissile fraction, and fissile plutonium fraction were determined for selected burnup levels (Table 4) as a function of time after discharge. All quantities are provided per initial mass of heavy metal (tHM) and per unit of energy produced (GWd).

The PWR fuel activity is lowest per tHM (Figure 5) but highest per GWd (Figure 6). LIFE fuels behave similarly per GWd, and thorium fuel performs better in terms of initial tHM. Higher burnups minimizes activity, regardless of normalization.

Decay heat is lower for thorium fuel than the PWR fuel, for either normalization and for used PWR LIFE fuel per GWd ( Figure 7 and Figure 8). Higher burnups minimize decay heat most effectively. Inhalation hazard behaves similarly to decay heat, as in Figure 9 and Figure 10. Relative performances are the same, and higher burnups most effectively minimizes inhalation hazard.

Ingestion hazard most effectively minimizes the PWR per initial tHM (Figure 11) and thorium per GWd (Figure 12). Higher burnups minimize ingestion hazard, however, the relative decrease in ingestion hazard as burnup increased is smaller than for inhalation hazard.

Neptunium-237 and precursor levels are graphed in Figure 13 and Figure 14. Thorium has the lowest levels for either normalization, as a result of the lower atomic mass of the fertile thorium fuel. In general, LIFE used PWR fuel performs the worst. The exception was the fuel at burnup of $99.441 \%$ FIMA. This has the lowest level per GWd and the second lowest level per tHM; thorium at burnup of $94.117 \%$ also effectively minimizes levels.

Total neutron source was graphed per initial tHM and GWd in Figure 15 and Figure 16. PWR fuel minimizes the levels most effectively. However, high neutron source levels could provide a benefit in terms of proliferation resistance, as materials are more difficult to handle with the large levels of emitted neutrons, so high total neutron source is a positive attribute. Total neutron source increases with increasing burnup. Fission product mass behaves similarly, with PWR most effectively minimizing the quantity both per initial tHM (Figure 17) and per GWd (Figure 18). Fission product mass level increases with increasing burnup, as there were more fissions, and by extension, more fission products.

TRU mass is graphed per initial tHM and GWd in Figure 19 and Figure 20. TRU mass is most effectively minimized by the PWR in terms of initial tHM and by LIFE per GWd. TRU mass decreases with burnup for LIFE used PWR fuel and increase for LIFE thorium fuel. LIFE fueled with used PWR at burnup of 99.441\% FIMA minimizes TRU most effectively for both normalizations. Fissile mass behaves similarly, with the exception that thorium fuel minimized the levels per tHM most effectively on average, as can be seen in Figure 21 and Figure 22. Similarly, LIFE fueled with used PWR at burnup of 99.441\% FIMA minimizes fissile mass most effectively for both normalizations.

Finally, fissile fraction and fissile plutonium fraction were analyzed in Figure 23 and Figure 24, respectively. The PWR fuel minimizes the fissile fraction most effectively, followed by thorium fuel. Fissile fraction decreased with increase burnup. LIFE fueled with used PWR at burnup of $99.441 \%$ FIMA with minimized fissile mass most effectively. There are no conclusive 
findings for fissile plutonium fraction. As can be seen in Figure 24, the fraction of fissile plutonium is highly dependent on time for both LIFE fuels.

In order to facilitate the analysis, each fuel was ranked for each characteristic on a relative scale (for both normalizations). Fuels were ranked from 1 (best at minimization of quantity) to 3 (worst). These were determined qualitatively from the graphs. If a clear hierarchy was not visible, the parameter was not analyzed. The results, including overall total rank, are given in Table 5. The best performing fuel is the one with the lowest "score." From this analysis, thorium fuel minimized hazards most effectively per GWd and used PWR fuel minimized hazards most effectively per initial tHM. However, per GWd, both LIFE fuels performed the most effectively.

However, a major exception to the general rules is the behavior of the used PWR fuel for LIFE at very high burnup. This, along with the thorium fuel at high burnup, minimized almost every category most effectively, for both normalizations. The only exceptions were fission product mass, which is reasonable because of the greater number of fissions. 


\section{Cask Loading}

In the previous section, it was shown that even if a LIFE engine reduces the amount of waste generated per unit of energy produced, the radiotoxicity and activity associated with this waste are greater - unless burnup above $99 \%$ are achieved - and provide waste management challenges. A more comprehensive comparison is provided by determine the storage requirements for the high level waste arise from each cycle. This will be accomplished by finding the optimal HLW stored in canisters, and by determining the number of canisters required. This measure combines the volume of waste with its radioactive hazard features.

First, the tools developed for this study were benchmarked against available results. A PWR case with burnup of $28 \mathrm{GWd}$ and $4.0 \mathrm{wt} \%{ }^{235} \mathrm{U}$ enrichment was analyzed via depletion in Origen-S followed by analysis via the MATLAB script. The same optimal solution was found in the literature, with $528 \mathrm{~kg}$ of HLW and $1505 \mathrm{~kg}$ of glass per canister. The test case feasibility solution and the benchmarked solution are available in Figure 25 and Figure 26. It can clearly be seen that the intersections of constraint 1 and 7 form the optimal solution.

With the code validated, test cases with burnup from $30.150 \%$ FIMA to $99.441 \%$ FIMA were tested for LIFE fueled with used PWR fuel and test cases with burnup from 30.013\% FIMA to $94.177 \%$ FIMA for LIFE fueled with thorium. Decay cooling times before loading between three and forty years were tested for both fuels. Several sample solution spaces are given. Figure 27 gives an optimal solution for thorium fuel with no THOREX extraction. The molybdenum trioxide constraint and mass constraint give the optimal cask loading. Figure 28 gives the solution space for used PWR fuel in LIFE that has been reprocessed via PUREX. The intersection of constraint 4, constraint 6 , and constraint 1 form the optimal solution. These three constraints were the most commonly constraining. The plutonium constraint (constraint 5) and sodium dioxide constraint (constraint 7) were never constraining for LIFE. The volume constraint (constraint 2) and mass of glass frit (constraint 3 ) were only constraining for nonreprocessed used nuclear fuel for LIFE and several thorium cases with THOREX reprocessing.

Table 6 contains data for optimum solutions after cooling of five years. There is less total waste when reprocessing is applied. Amount of waste stored per container tends to be larger for smaller burnups. Figure 29, Figure 30, Figure 31, and Figure 32 compare data from Table 6. Figure 29 shows the large increase of total HLW per initial tHM of LIFE relative to reprocessed PWR. PWR fuel with reprocessing, at $50 \mathrm{GWd} / \mathrm{tHM}$ offers the greatest waste reduction per initial mass of heavy metal. This is due to the large amounts of uranium and plutonium that can be removed that comprise a higher fraction of the waste. It also shows the increase in total HLW for higher burnup. Figure 30 shows the comparable levels of waste when normalized per GWd for LIFE and LWR. This is because of increased energy gained from deepburn in LIFE. It also shows the decrease in HLW per GWd as total burnup increases. Figure 31 gives the number of canisters required to store one initial tonne of HLW waste. Since this is dependent on both the cask loading optimal solution and total HLW, there is no clear relationship between burnup and number of cask. In general, thorium fuel required similar numbers of canisters regardless of reprocessing and used PWR fuel required fewer canisters with PUREX. Figure 32 shows the comparable levels of canisters needed per GWd between LIFE and LWR. It also shows a clear decrease in number of canisters required as burnup increases.

In order to eliminate decay heat as a constraint, the waste was allowed to cool for longer periods of time until the constraint (4) was not limiting. This allowed some of the shorter lived isotopes to decay away and decrease overall heat emission. This meant that the optimal solution was constrained by constraint 1 (total mass of container) and constraint 3 (mass fraction of the 
glass frit) or constraint 4 (molybdenum trioxide wt \%). Cooling times required are given in Figure 33. It was found that the decay heat constraint can be eliminated for all systems with acceptable cooling time - 40 years or less. LIFE fueled with used PWR required longer cooling times relative to thorium. Higher burnups tended to require less, or no, additional cooling beyond five years. Tabular date is given in Table 7. Higher burnups tended to have overall better performances in the categories of total waste and number of canisters required. To aid analysis, data from Table 7 is graphed and compared. Figure 34 shows the total HLW normalized per initial tHM after additional cooling. Total HLW is independent of decay constant, so these values are the same as before additional cooling time (seen in Figure 29 and Figure 30). Figure 36 shows the number of canisters required to store the waste per initial tHM. Despite the longer cooling time, PWR reprocessed with PUREX fuel was much more efficiently stored per initial tHM There is a clear increase in number of canisters needed with burnup, in order to accommodate higher levels of waste. In Figure 37, there is a decrease in number of canisters needed. The maximum canister savings for the thorium fuel was 1.5 canisters per initial tHM, but the maximum canister loading savings for the used nuclear fuel for LIFE was 3.6 canisters per initial tHM.

Figure 35 shows the total HLW normalized per GWd, respectively after additional cooling. The increase in energy produced per canister is graphed in Figure 38. Nearly all LIFE fuels required fewer canisters than the LWR reprocessed fuel per GWd. The main benefit of the longer cooling time can be seen in Table 8 where there were both increases in energy content per canister in $\mathrm{GWd}$ ), which is graphed in Figure 38. Optimized cooling time led to increases in energy content in LIFE fuels so that they were higher than for the PWR, except for lower burnups of LIFE used PWR fuel. The burnup required for increased performance over the PWR is $70 \%$ FIMA. The benefit was greatest for the LIFE system fueled with used PWR fuel, as it tended to have more short lived fission products. However, at higher burnups, the decay heat tended was not normally constraining and the additional cooling time did not affect the optimum solution.

Reprocessing and removal of fission products and uranium and plutonium offered both benefits and disadvantages. Firstly, it reduced the total level of high level waste, so there was less HLW to store. However, by decreasing the overall waste to store, it increased the molybdenum trioxide fraction, another constraint. Heat emission per unit volume increased, leading to a lower threshold for constraint 4. This meant that less HLW waste could be stored per canister. However, for nearly all cases, the reprocessing led to less overall canisters, despite the decrease in the amount of waste stored per canister. Negative effects from heat emission were mitigated by longer optimized cooling times.

There are several limitations to this section of the study. Firstly, LIFE spent fuel is unlikely to be reprocessed using the PUREX or THOREX method, as there is already high burnup from LIFE. However, some processing is necessary and the assumption of PUREX or THOREX allows for a better comparison, and allows for calculation of glass frit mass needed. THOREX is also an experimental procedure and would require different processing chemicals. For simplicity and comparison, it was assumed that the process chemicals were similar. Additionally, it was assumed that the amount of process and corrosion chemicals required was linear proportional to the mass of HLW. Finally, heavy metals were extracted via the PUREX or THOREX processes were not accounted for in final waste disposal. Those heavy metals would still need to be disposed of in some form, even if they were refabricated into fuel and reused. 
Table 4: Burnups analyzed for LIFE engine

\begin{tabular}{|c|c|c|c|}
\hline \multicolumn{2}{|c|}{ Used PWR Fuel } & \multicolumn{2}{|c|}{ Thorium Fuel } \\
\hline FIMA $(\%)$ & Burnup (GWd/tHM) & FIMA $(\%)$ & Burnup (GWd/tHM) \\
\hline 50.147 & 490.8 & 50.138 & 478.6 \\
\hline 70.528 & 688.1 & 70.059 & 671.7 \\
\hline 90.045 & 879.5 & 90.007 & 862.7 \\
\hline 99.441 & 9718 & 04177 & 901.3 \\
\hline
\end{tabular}

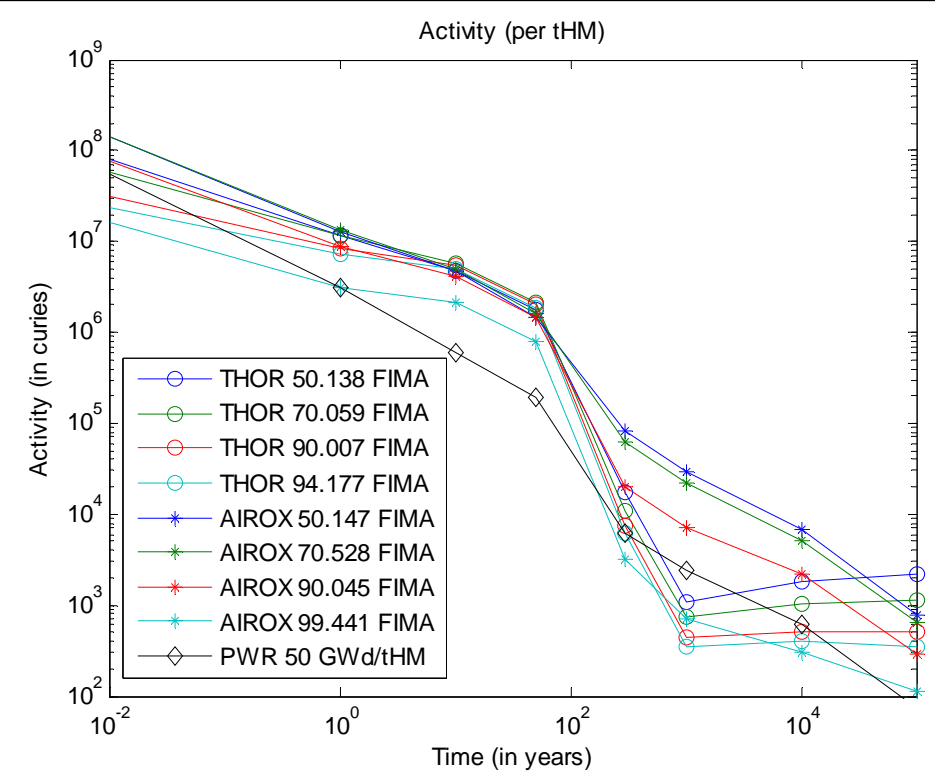

Figure 5: Activity variation for LIFE fueled with either AIROX reprocessed fuel or thorium compared to a traditional 50 GWd/tHM PWR (normalized per tHM)

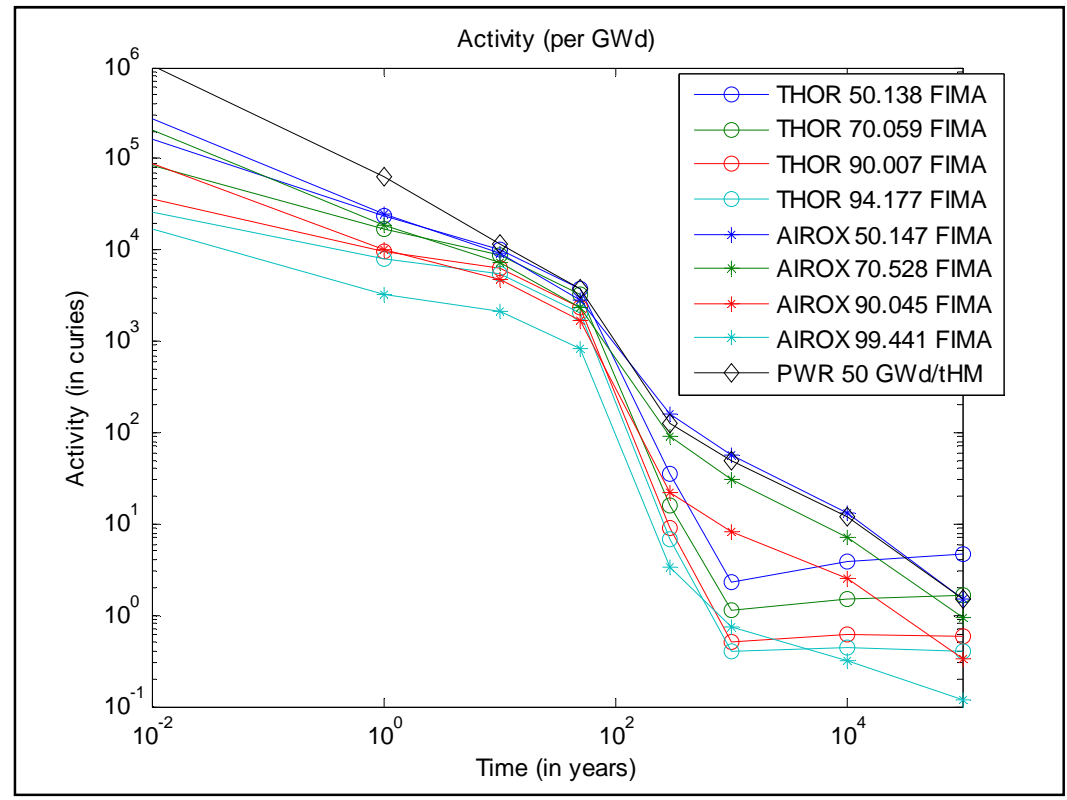

Figure 6: Activity variation for LIFE fueled with either AIROX reprocessed fuel or thorium compared to a traditional 50 GWd/tHM PWR (normalized per GWd) 


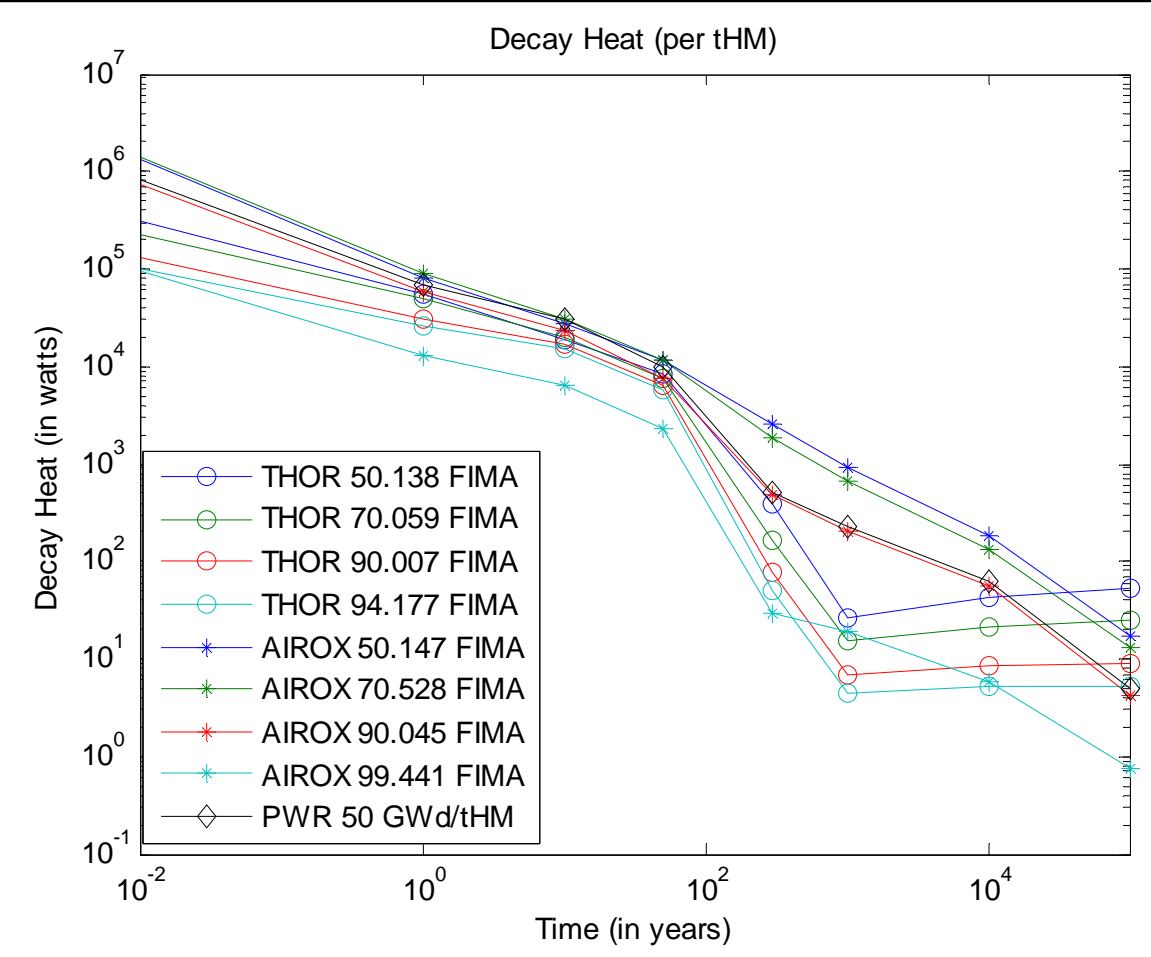

Figure 7: Decay heat variation for LIFE fueled with either AIROX reprocessed fuel or thorium compared to a traditional $50 \mathrm{GWd} / \mathrm{tHM}$ PWR (normalized per tHM)

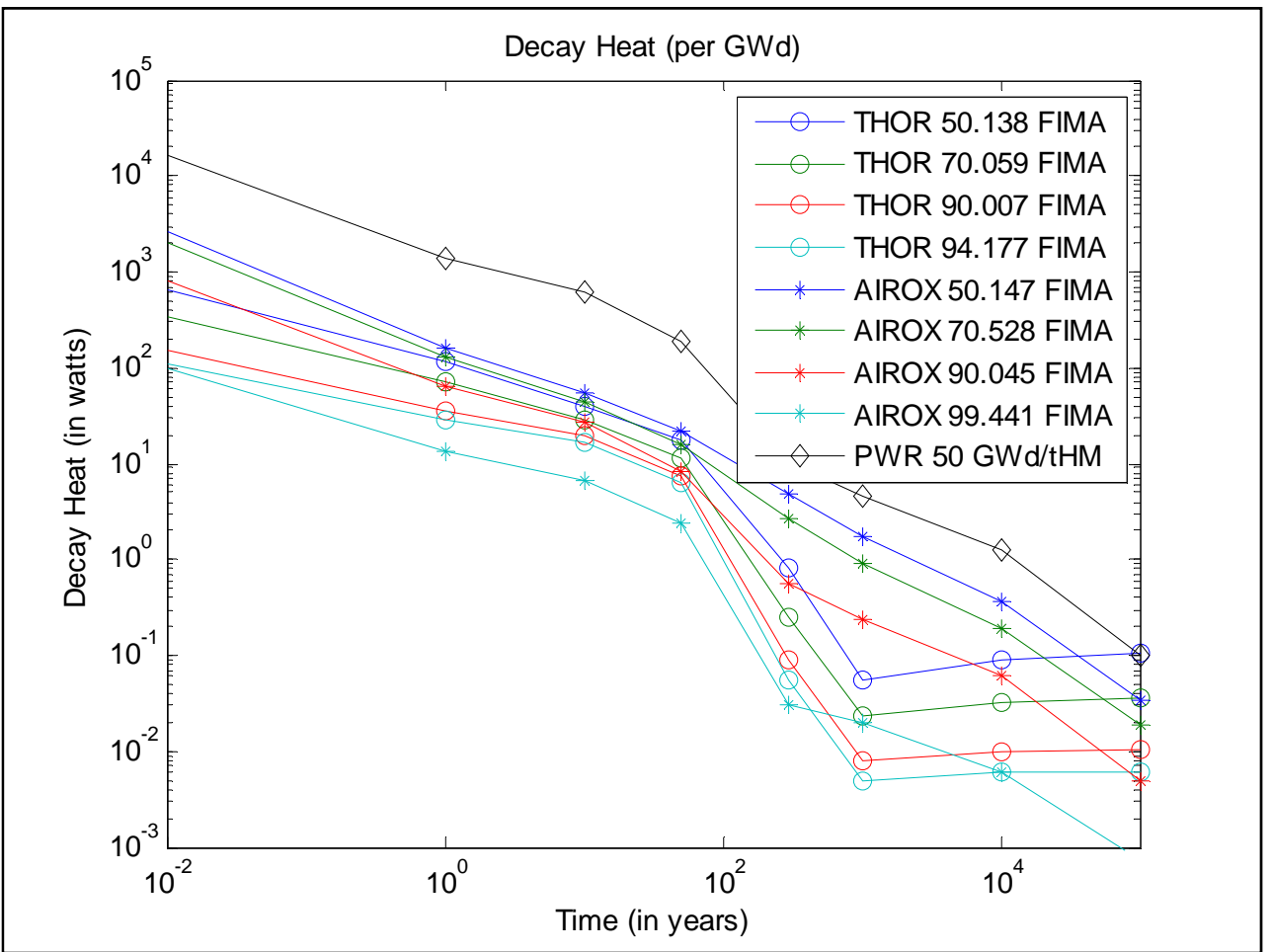

Figure 8: Decay heat variation for LIFE fueled with either AIROX reprocessed fuel or thorium compared to a traditional 50 GWd/tHM PWR (normalized per GWd) 


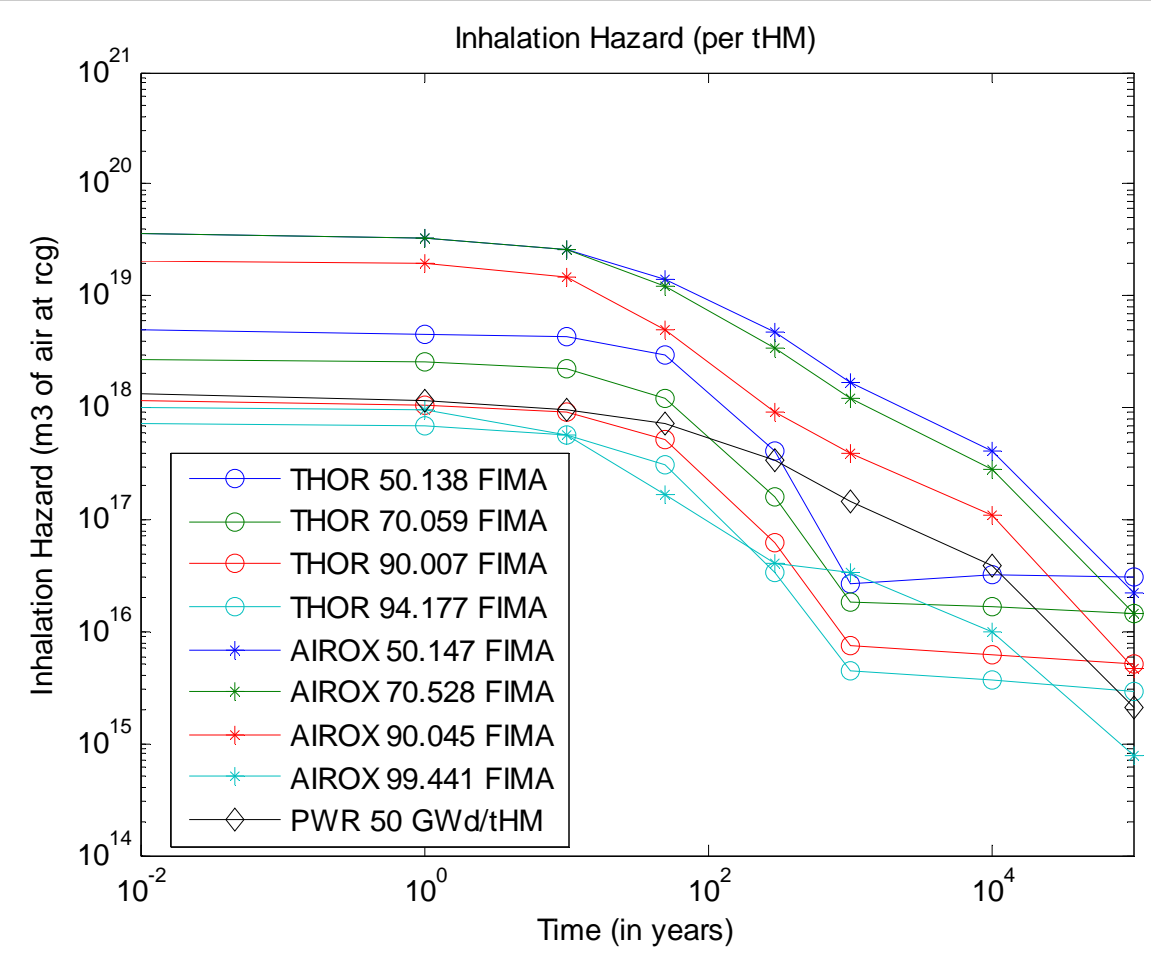

Figure 9: Inhalation hazard variation for LIFE fueled with either AIROX reprocessed fuel or thorium compared to a traditional 50 GWd/tHM PWR (normalized per tHM)

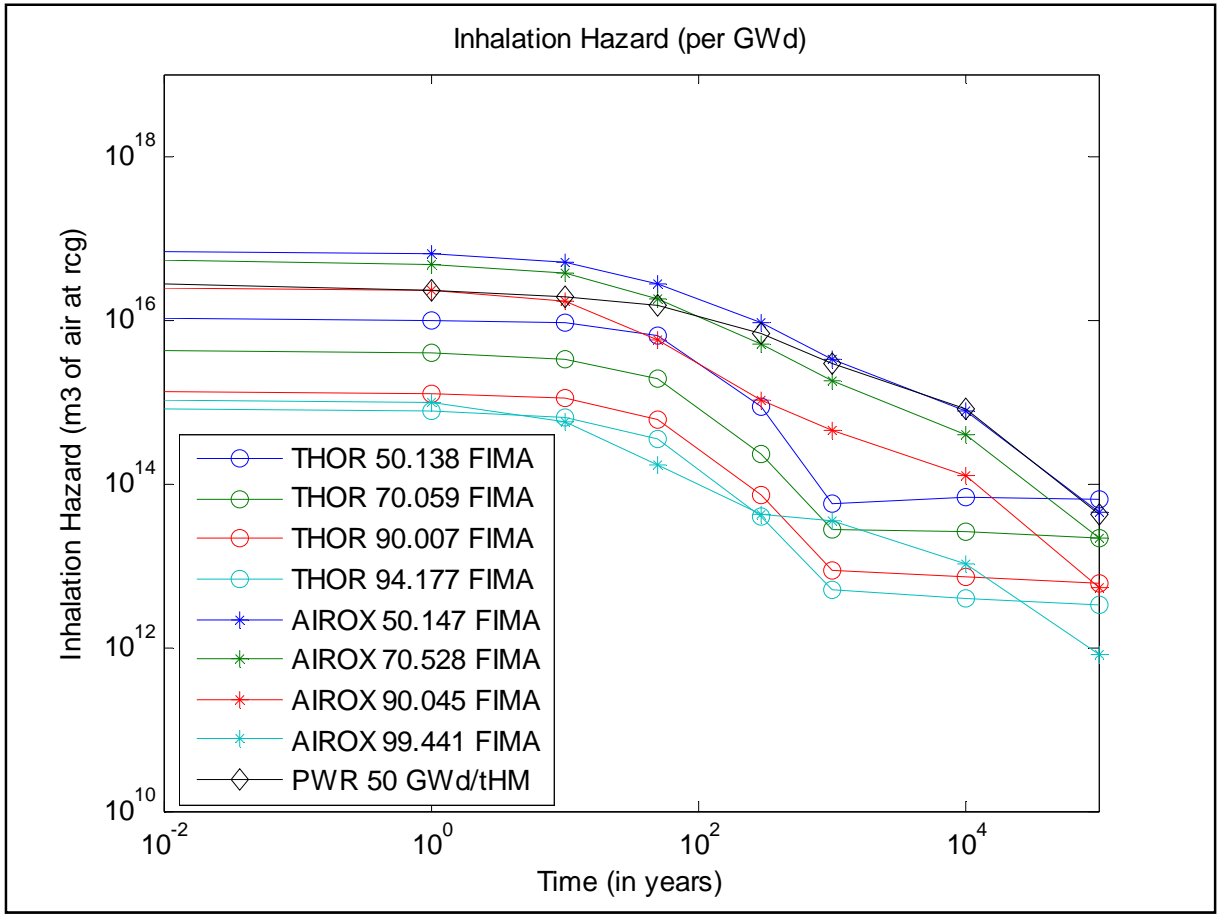

Figure 10: Inhalation hazard variation for LIFE fueled with either AIROX reprocessed fuel or thorium compared to a traditional 50 GWd/tHM PWR (normalized per GWd) 


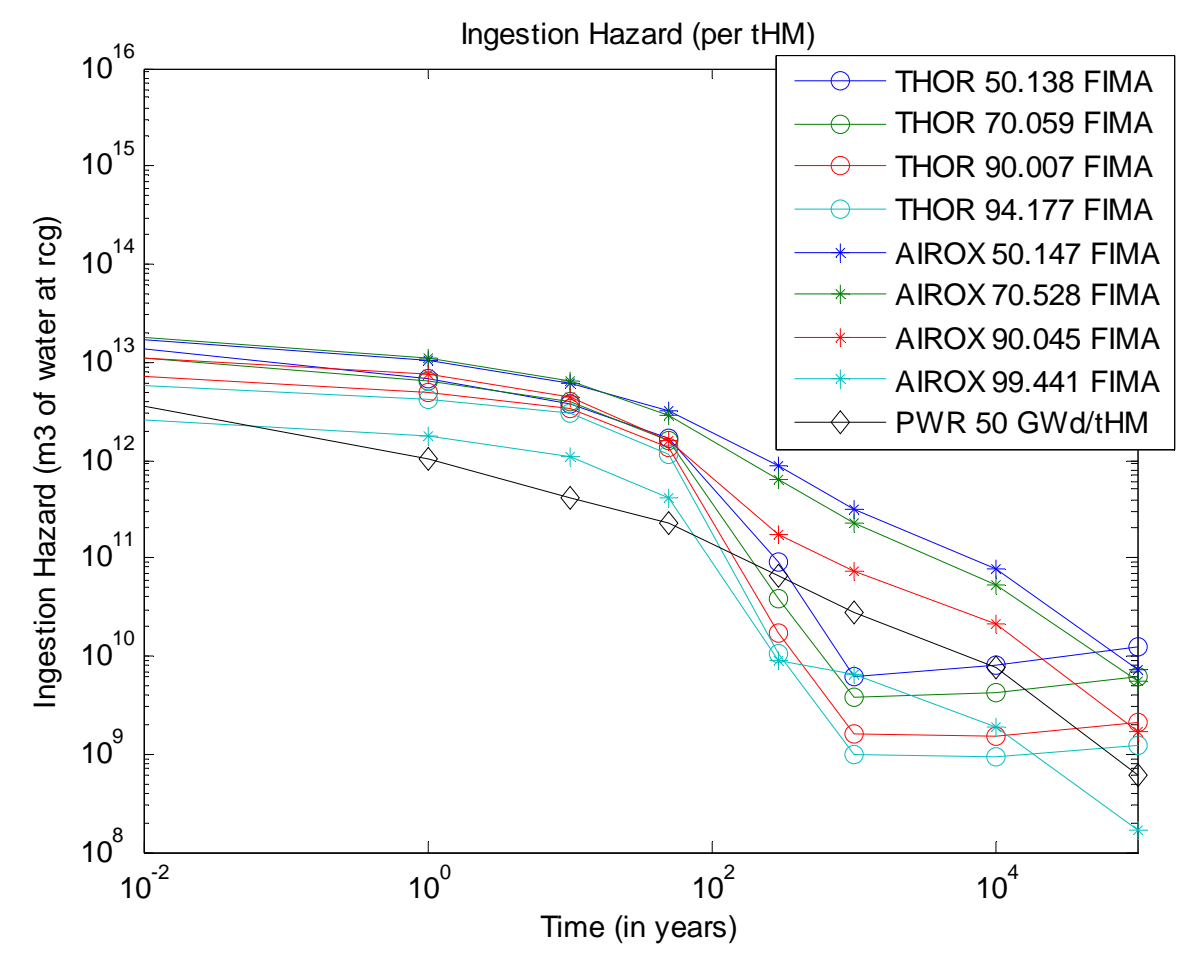

Figure 11: Ingestion hazard variation for LIFE fueled with either AIROX reprocessed fuel or thorium compared to a traditional 50 GWd/tHM PWR (normalized per tHM)

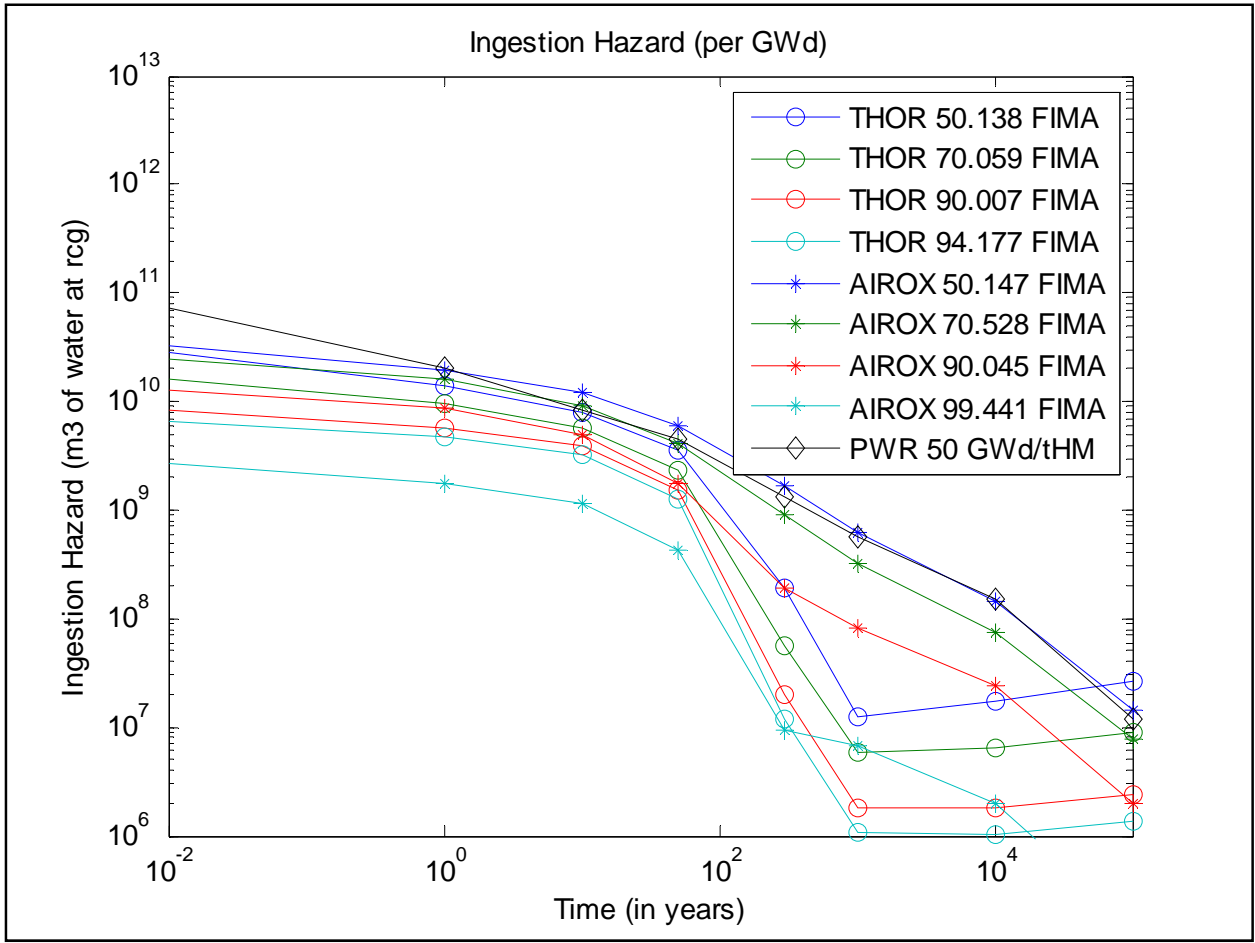

Figure 12: Ingestion hazard variation for LIFE fueled with either AIROX reprocessed fuel or thorium compared to a traditional 50 GWd/tHM PWR (normalized per GWd) 


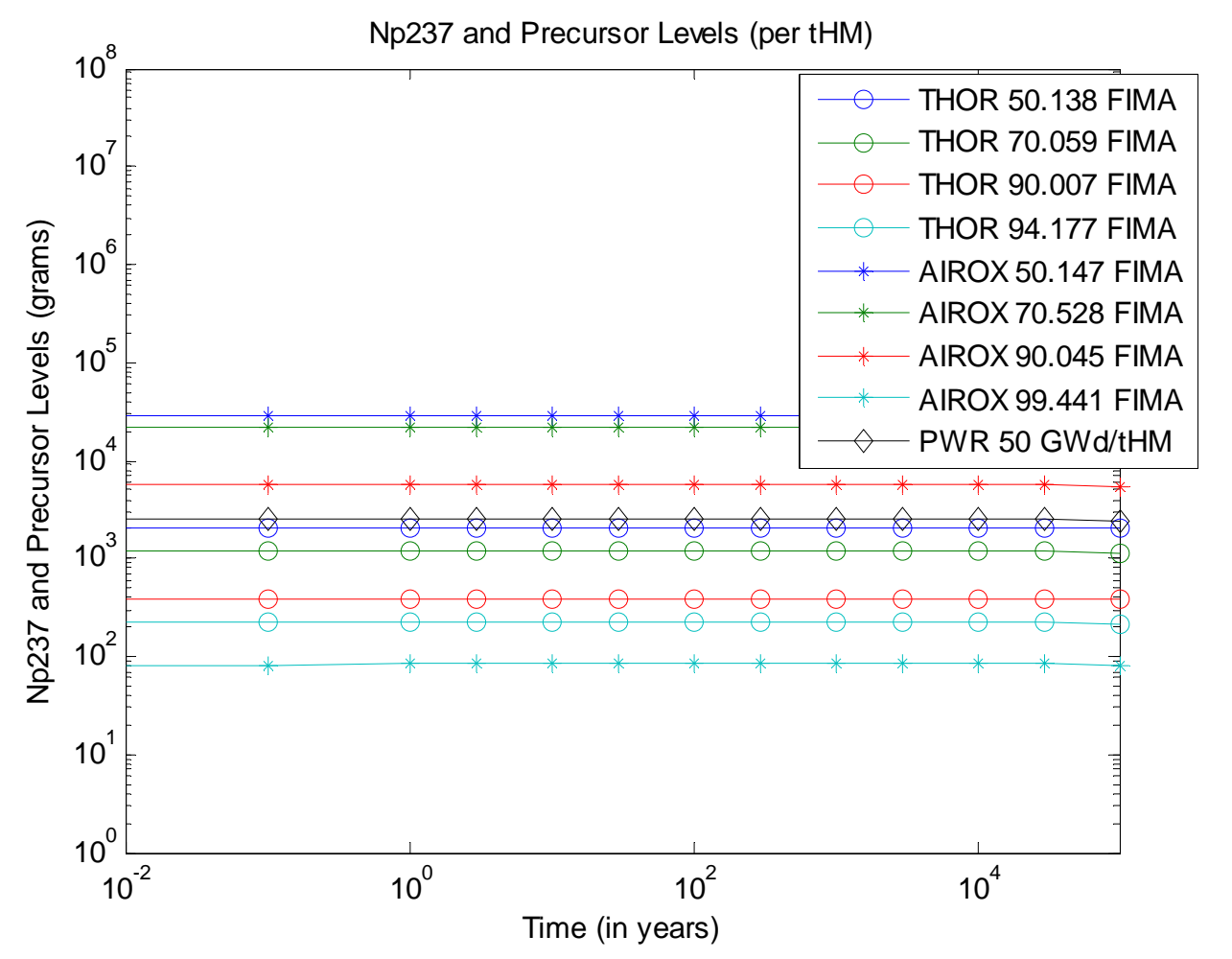

Figure 13: Np237 and precursor levels for LIFE fueled with either AIROX reprocessed fuel or thorium compared to a traditional 50 GWd/tHM PWR (normalized per GWd)

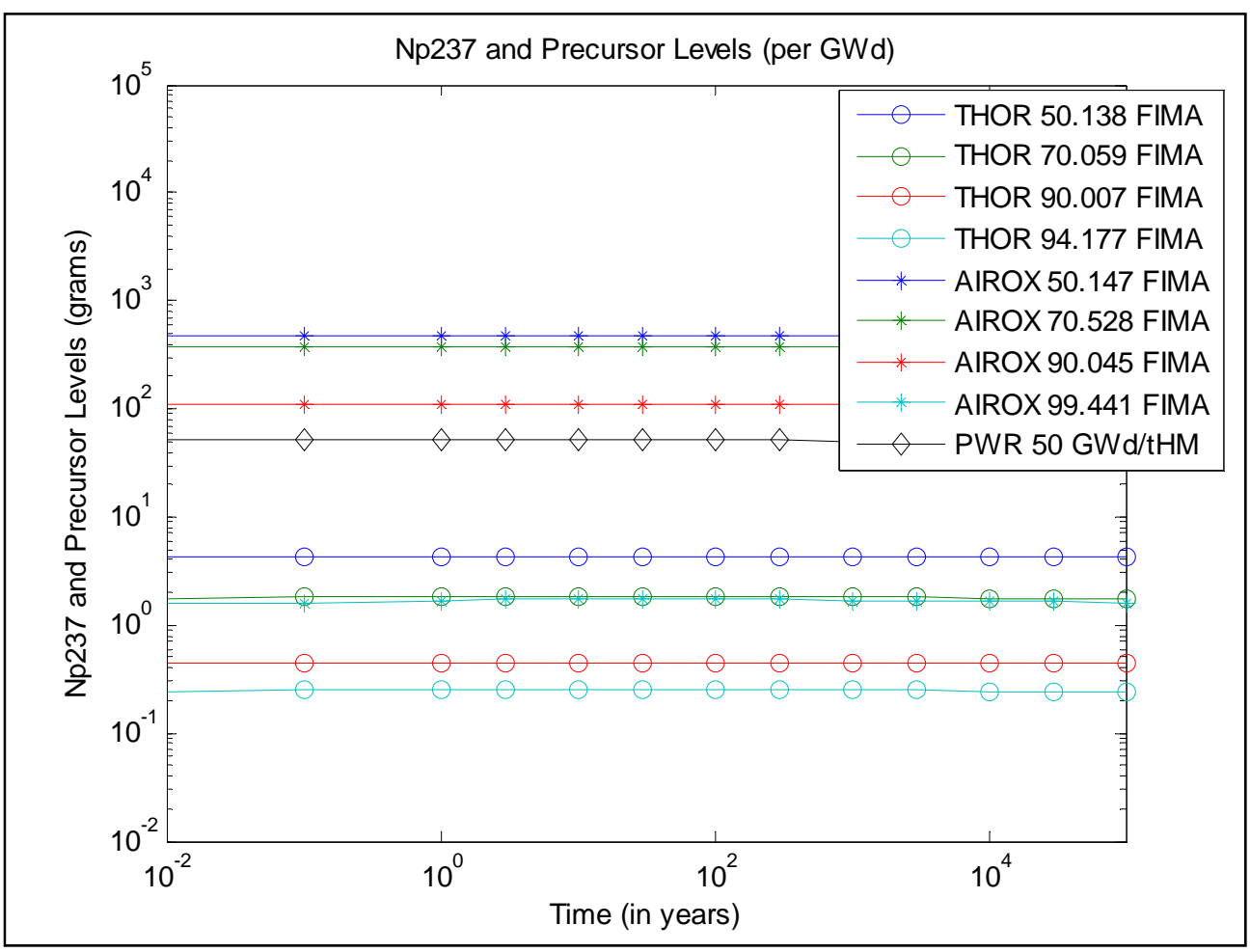

Figure 14: Np237 and precursors for LIFE fueled with either AIROX reprocessed fuel or thorium compared to a traditional 50 GWd/tHM PWR (normalized per GWd) 


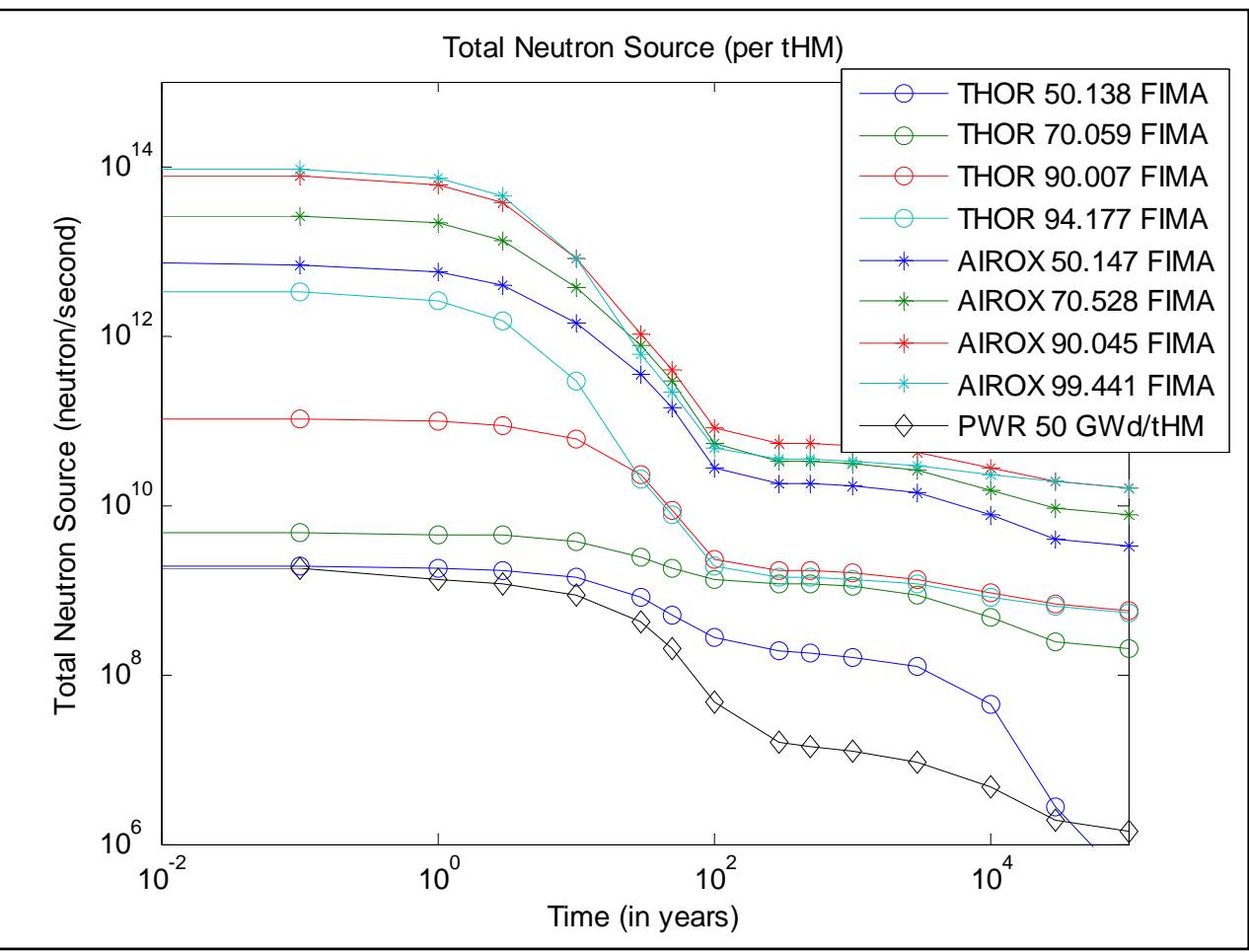

Figure 15: Total neutron source for LIFE fueled with either AIROX reprocessed fuel or thorium compared to a traditional 50 GWd/tHM PWR (normalized per tHM)

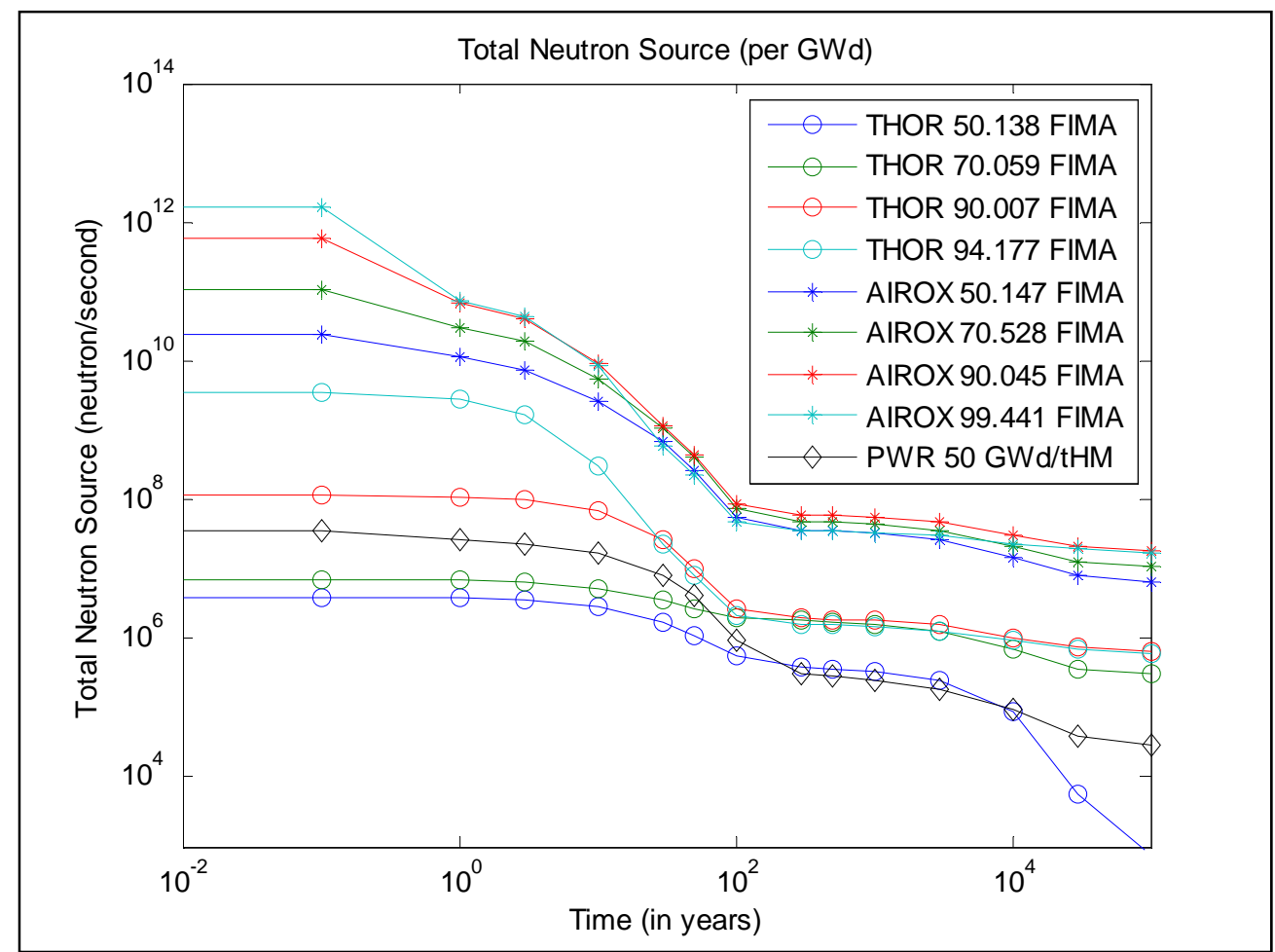

Figure 16: Total neutron source for LIFE fueled with either AIROX reprocessed fuel or thorium compared to a traditional 50 GWd/tHM PWR (normalized per GWd) 


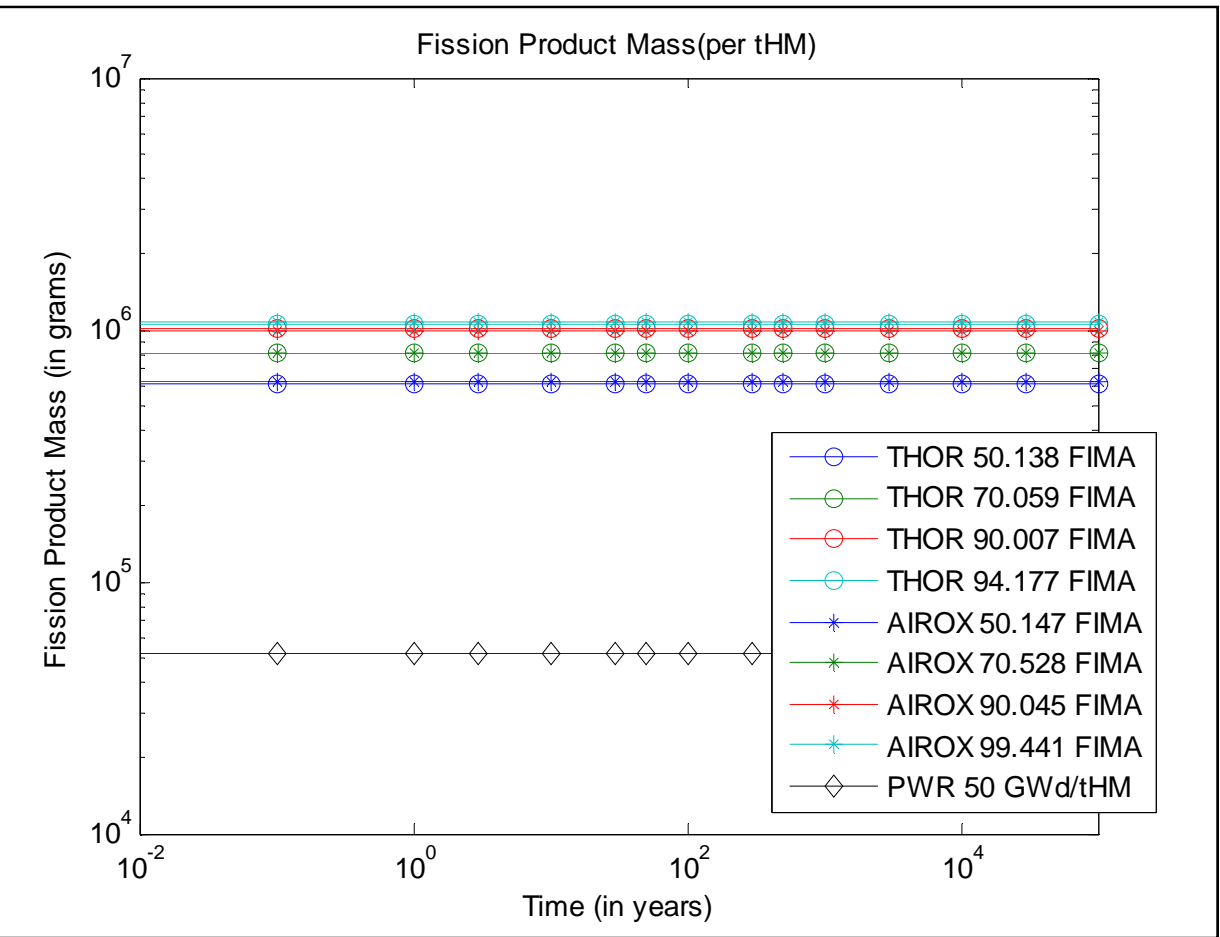

Figure 17: Fission product mass for LIFE fueled with either AIROX reprocessed fuel or thorium compared to a traditional 50 GWd/tHM PWR (normalized per tHM)

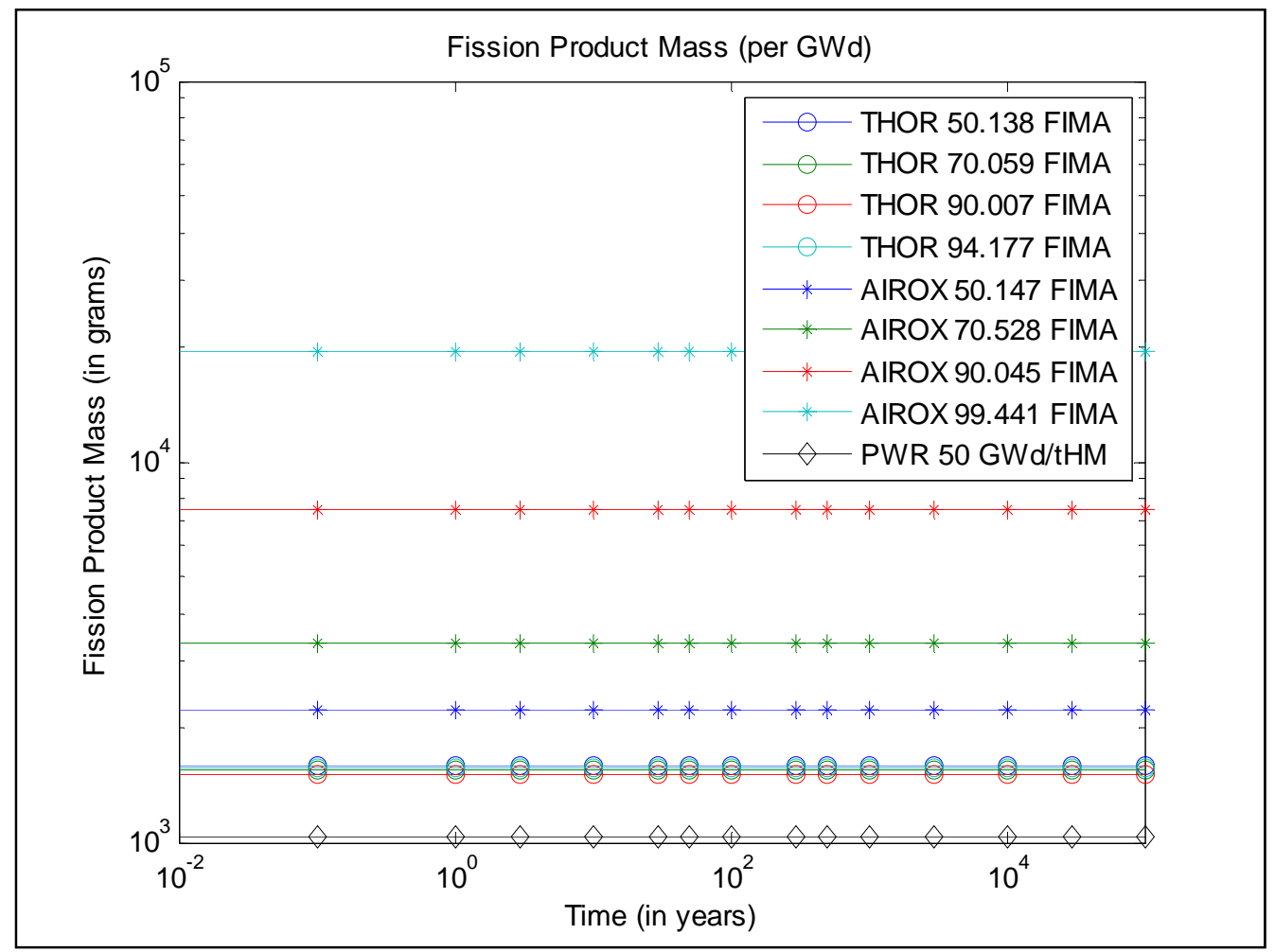

Figure 18: Fission product mass for LIFE fueled with either AIROX reprocessed fuel or thorium compared to a traditional 50 GWd/tHM PWR (normalized per GWd) 


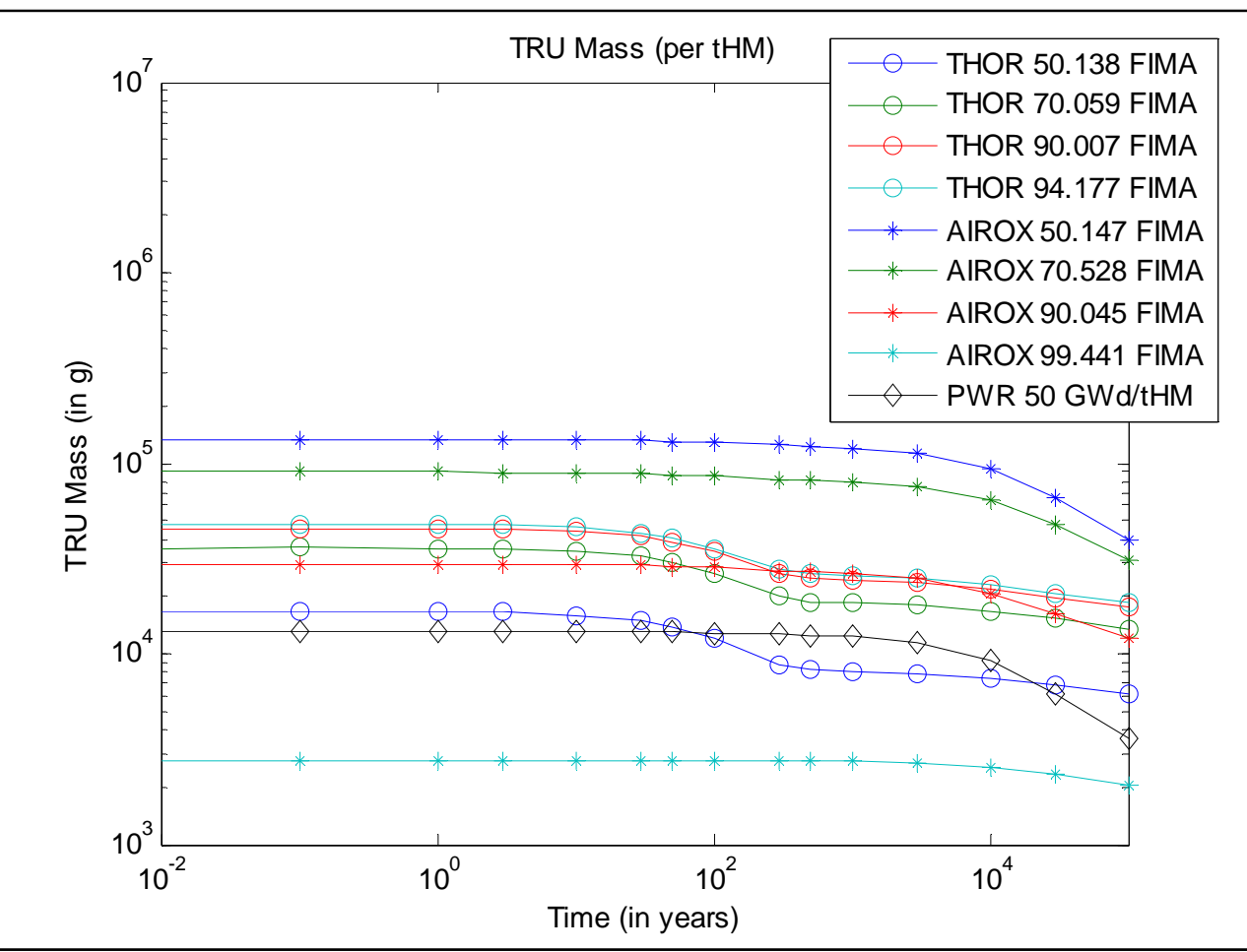

Figure 19: TRU mass for LIFE fueled with either AIROX reprocessed fuel or thorium compared to a traditional 50 GWd/tHM PWR (normalized per tHM)

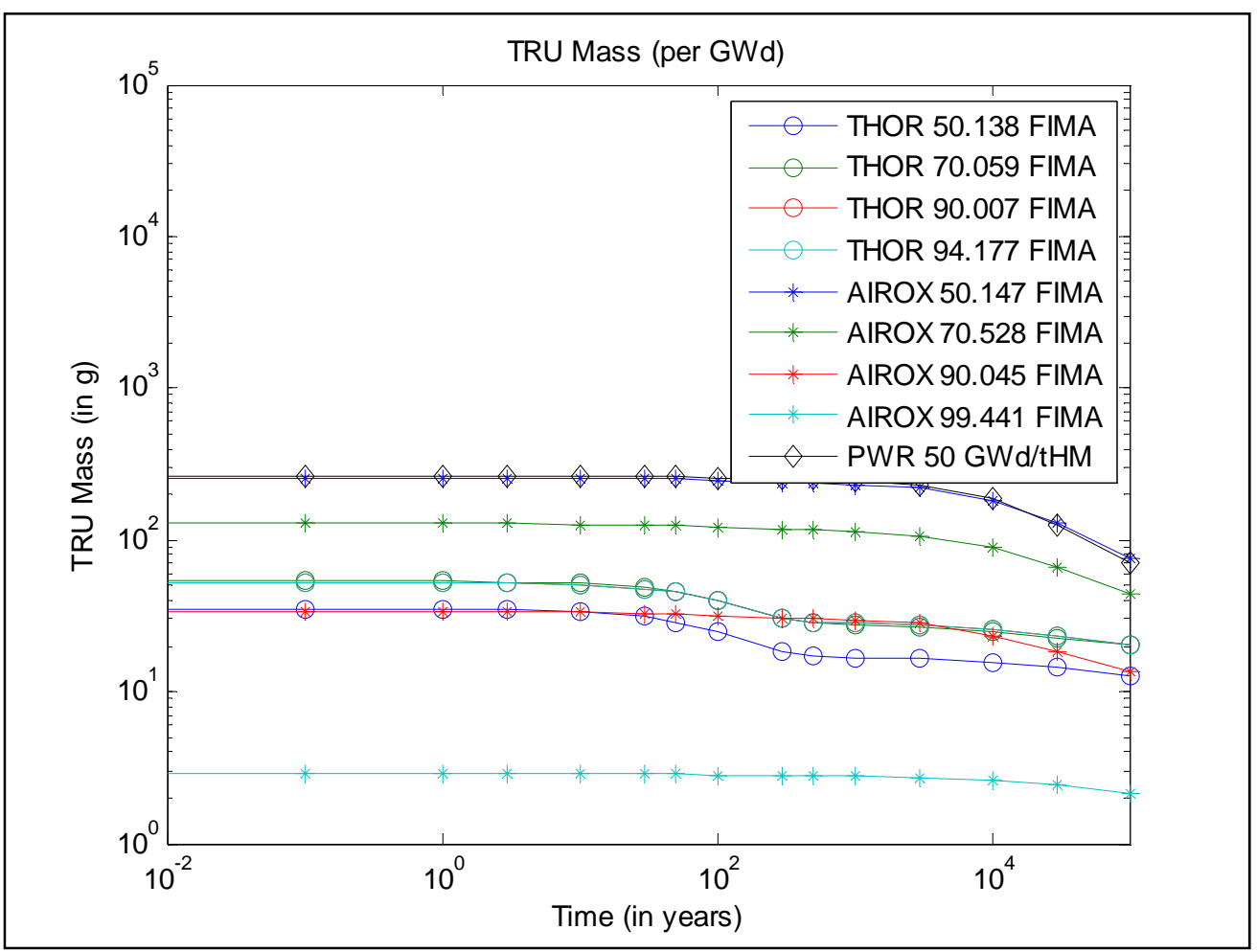

Figure 20: TRU mass for LIFE fueled with either AIROX reprocessed fuel or thorium compared to a traditional 50 GWd/tHM PWR (normalized per GWd) 


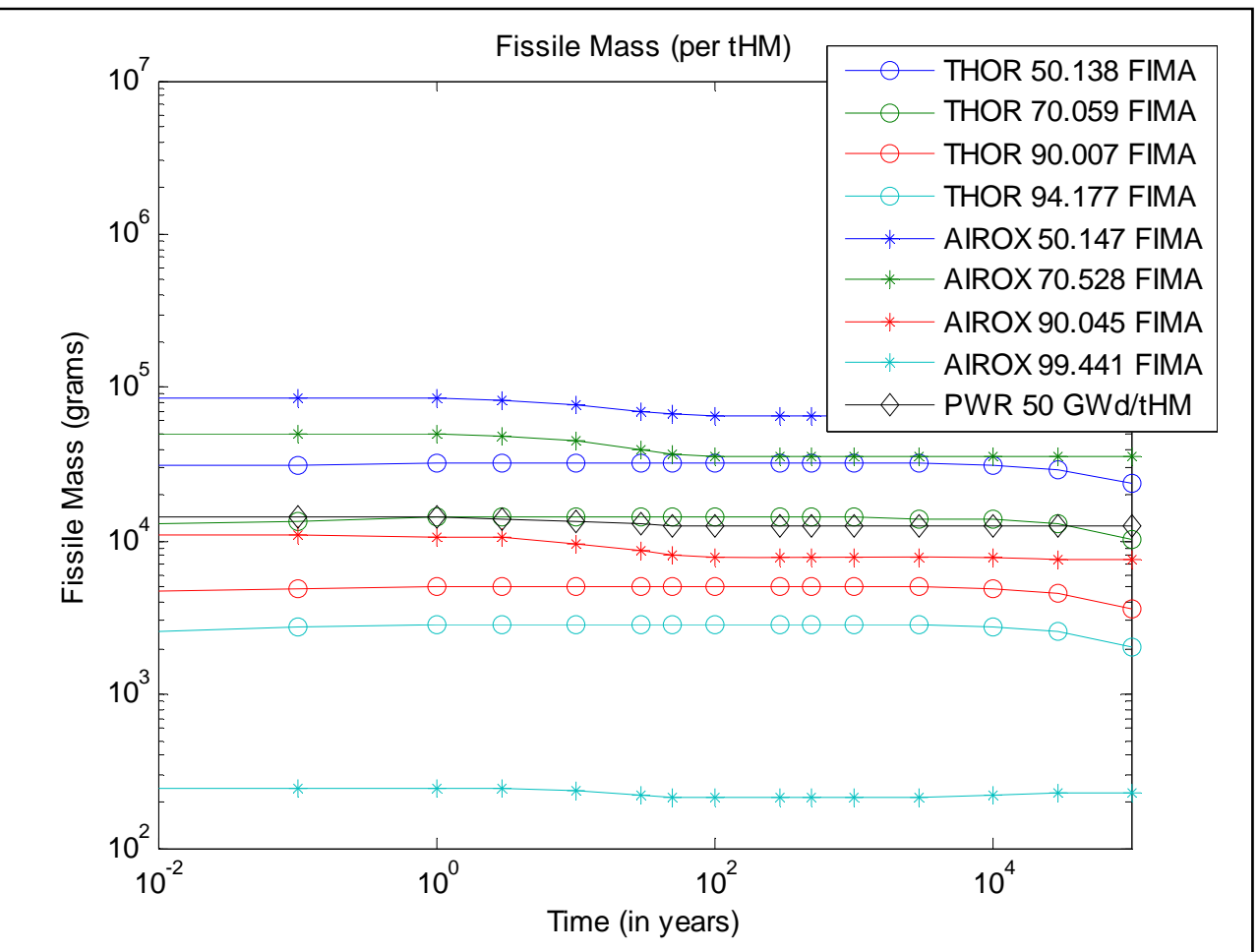

Figure 21: Fissile mass for LIFE fueled with either AIROX reprocessed fuel or thorium compared to a traditional 50 GWd/tHM PWR (normalized per tHM)

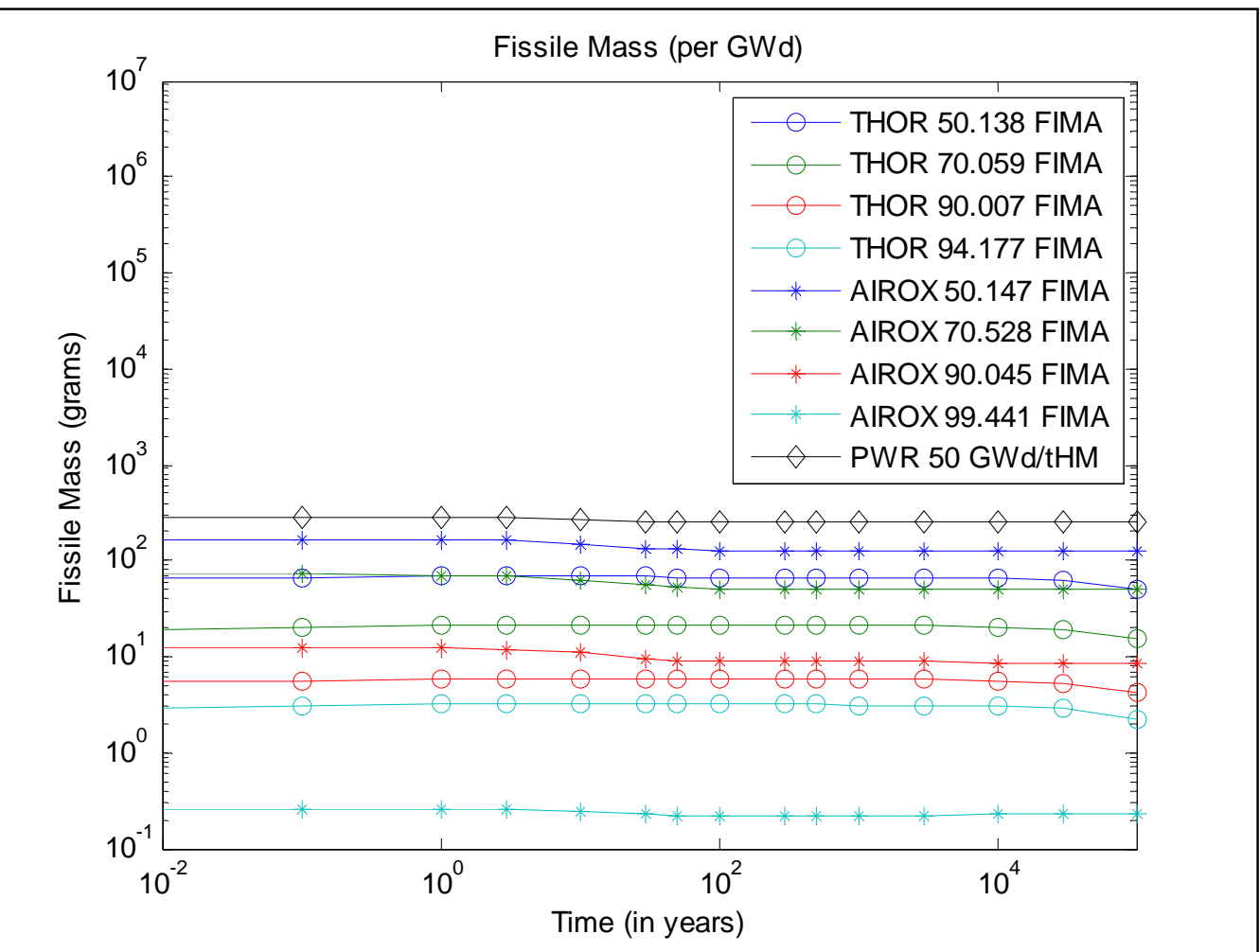

Figure 22: Fissile mass for LIFE fueled with either AIROX reprocessed fuel or thorium compared to a traditional 50 GWd/tHM PWR (normalized per GWd) 


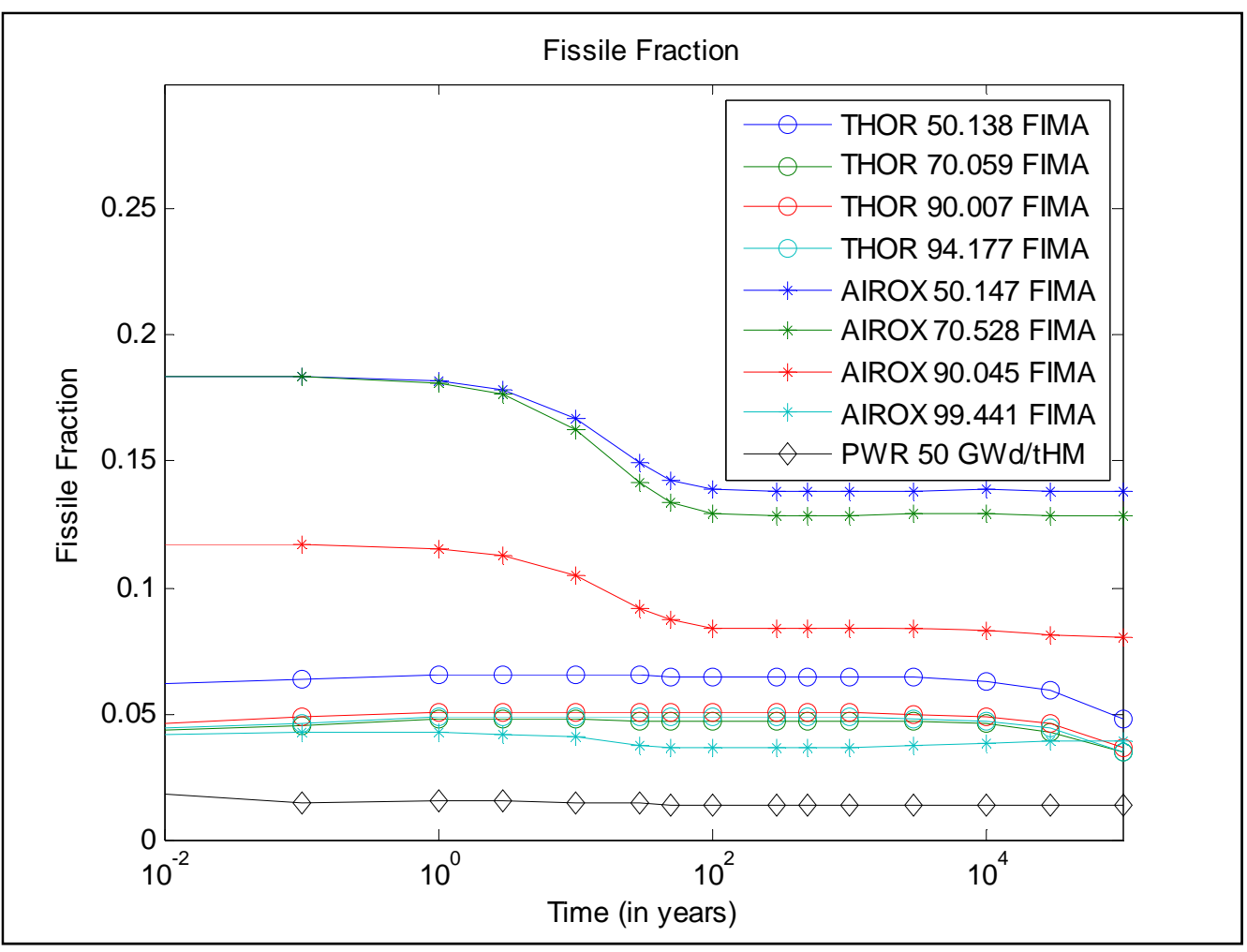

Figure 23: Fissile fraction for LIFE fueled with either AIROX reprocessed fuel or thorium compared to a traditional 50 GWd/tHM PWR

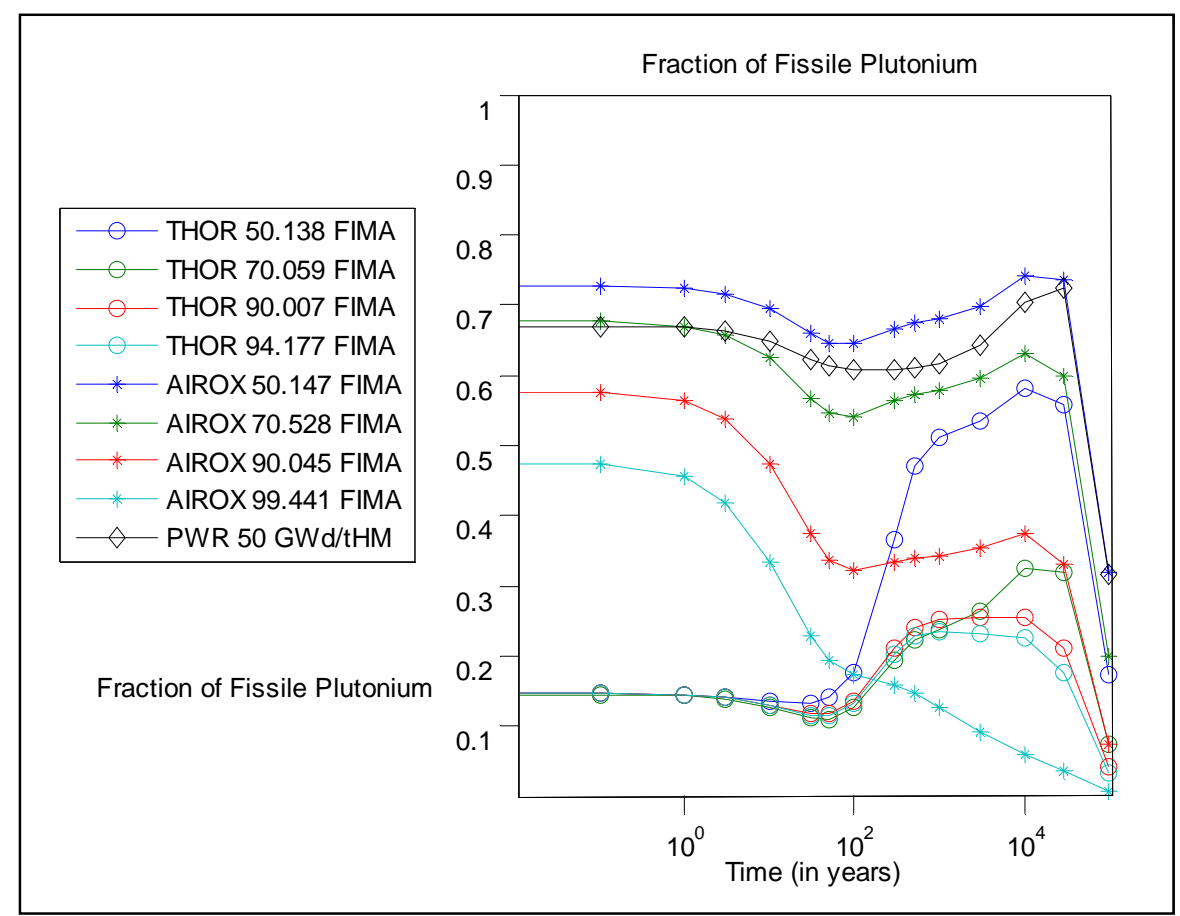

Figure 24: Plutonium fraction for LIFE fueled with either AIROX reprocessed fuel or thorium compared to a traditional 50 GWd/tHM PWR 
Table 5: Rank of various parameters related to repository performance

\begin{tabular}{|c|c|c|c|c|c|c|}
\hline & \multicolumn{3}{|c|}{ Per tHM } & \multicolumn{3}{|c|}{ Per GWd } \\
\hline & $\begin{array}{l}\text { Used PWR } \\
\text { LIFE fuel }\end{array}$ & Thorium & PWR & $\begin{array}{l}\text { Used PWR } \\
\text { LIFE fuel }\end{array}$ & Thorium & PWR \\
\hline Activity & 2 & 3 & 1 & 1 & 1 & 3 \\
\hline Decay Heat & 3 & 1 & 2 & 2 & 1 & 3 \\
\hline Inhalation Hazard & 3 & 1 & 2 & 2 & 1 & 3 \\
\hline Ingestion Hazard & 3 & 2 & 1 & 2 & 1 & 3 \\
\hline Np-237 and Precursors & 3 & 1 & 2 & 3 & 1 & 2 \\
\hline Total Neutron Source & 1 & 2 & 3 & 1 & 2 & 3 \\
\hline Fission Product Mass & 2 & 2 & 1 & 3 & 2 & 1 \\
\hline TRU Mass & 3 & 2 & 1 & 1 & 1 & 3 \\
\hline Fissile Mass & 3 & 1 & 2 & 1 & 1 & 3 \\
\hline Fissile Fraction & 3 & 2 & 1 & 3 & 2 & 1 \\
\hline Total & 26 & 17 & 16 & 19 & 13 & 25 \\
\hline
\end{tabular}




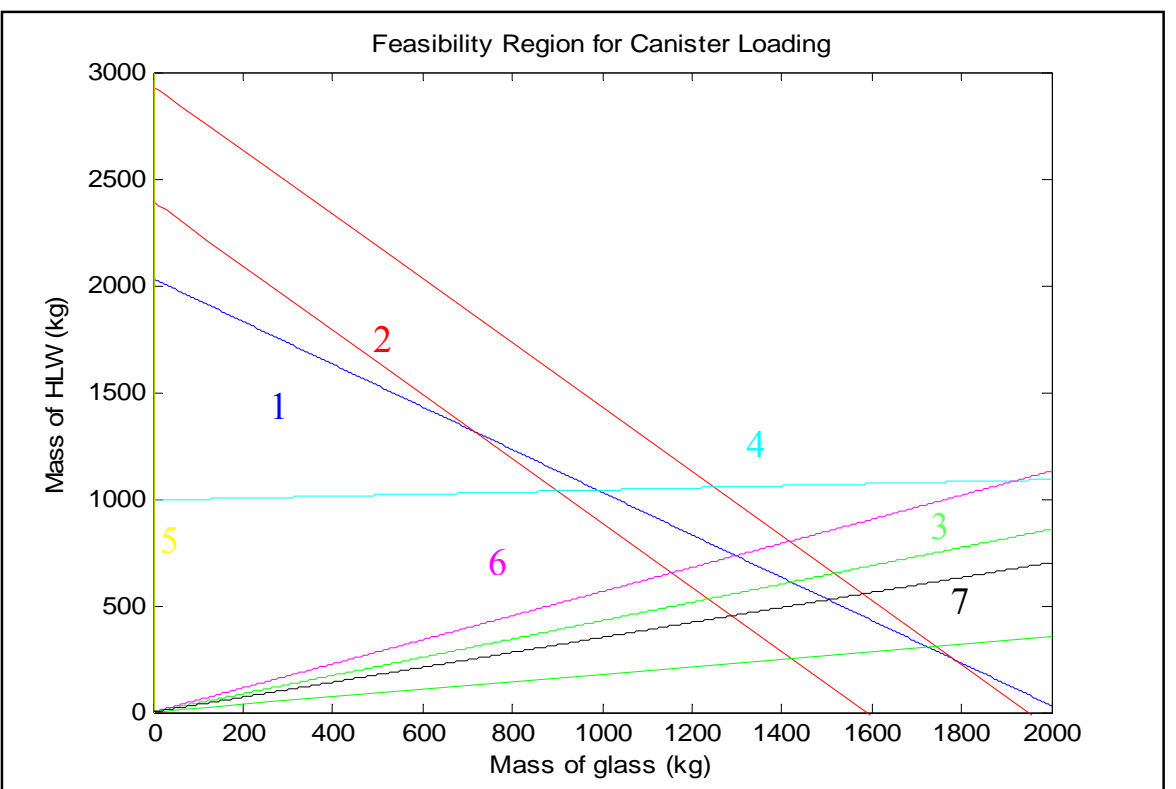

Figure 25: $28 \mathrm{GWd} / \mathrm{tHM}$ metal burnup, $4.0 \mathrm{wt} \%{ }^{235} \mathrm{U}$ benchmark solution for PWR

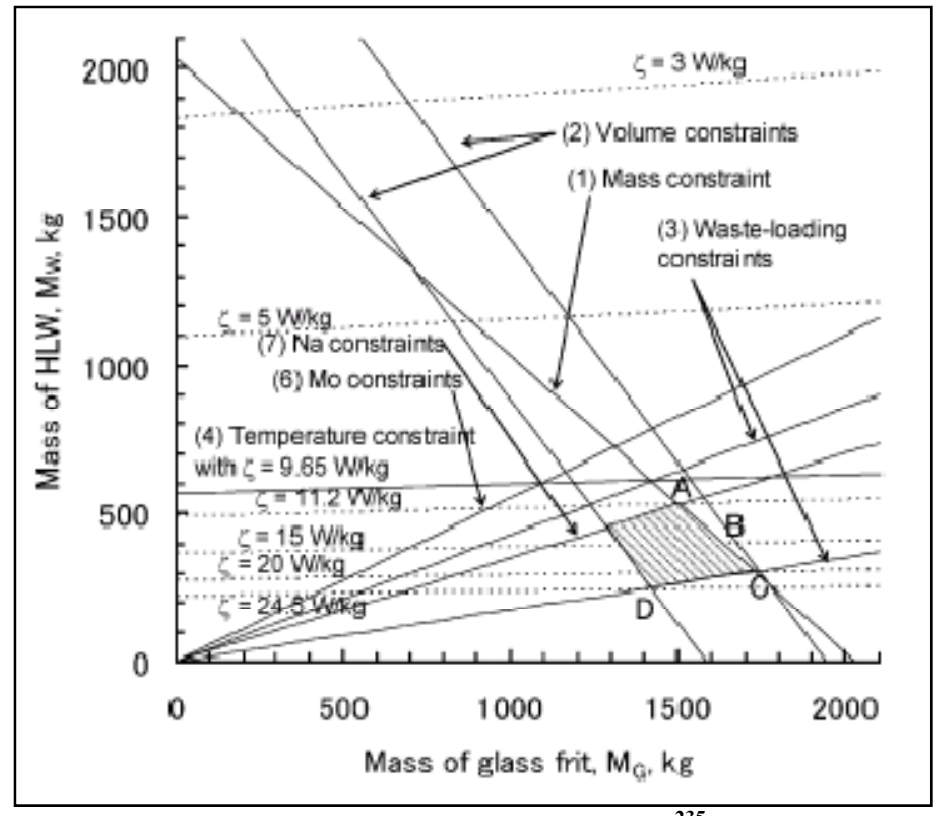

Figure 26: $28 \mathrm{GWd} / \mathrm{tHM}$ metal burnup, $4.0 \mathrm{wt} \%{ }^{235} \mathrm{U}$ benchmark solution for PWR from Ahn 


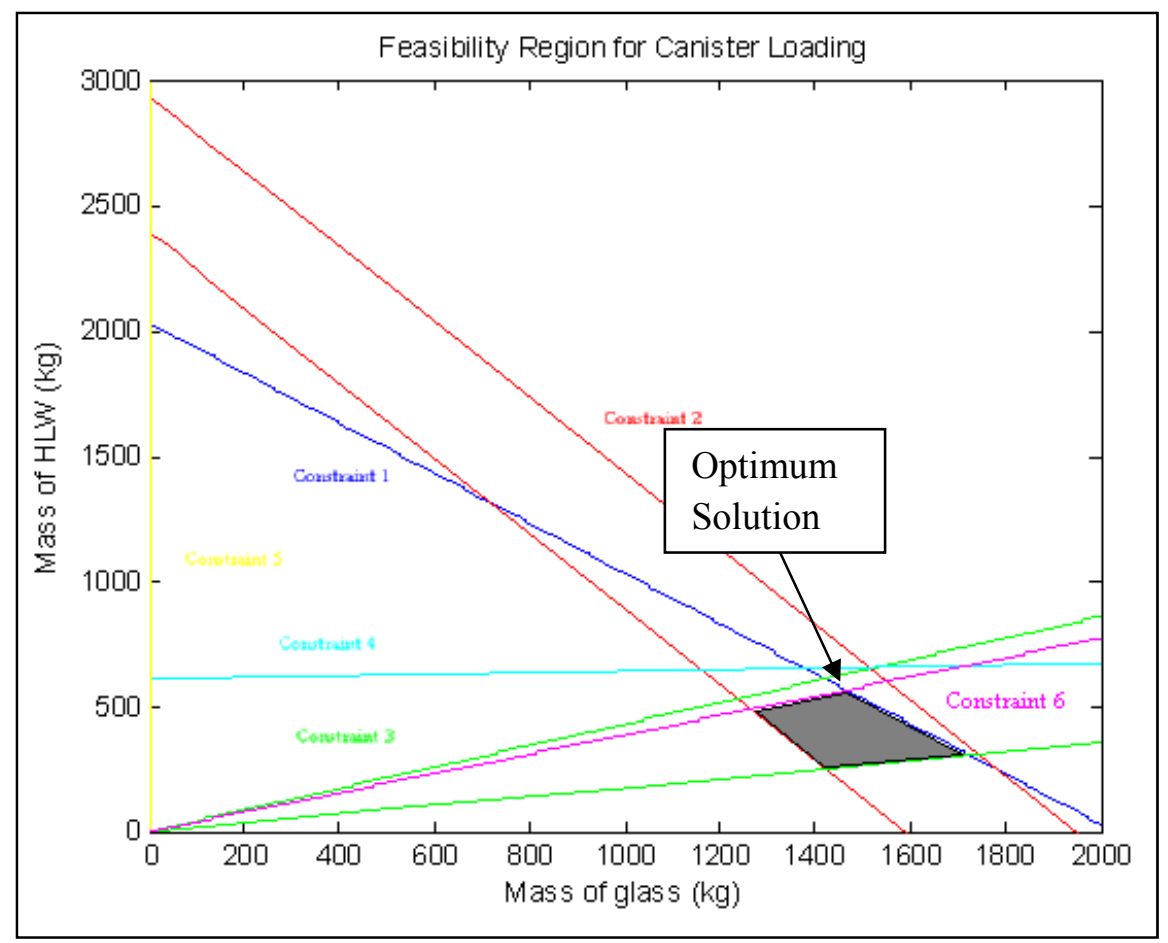

Figure 27: Feasibility Solution for BU $=90 \%$ FIMA and cooling of 5 years for LIFE with thorium fuel (THOREX not used)

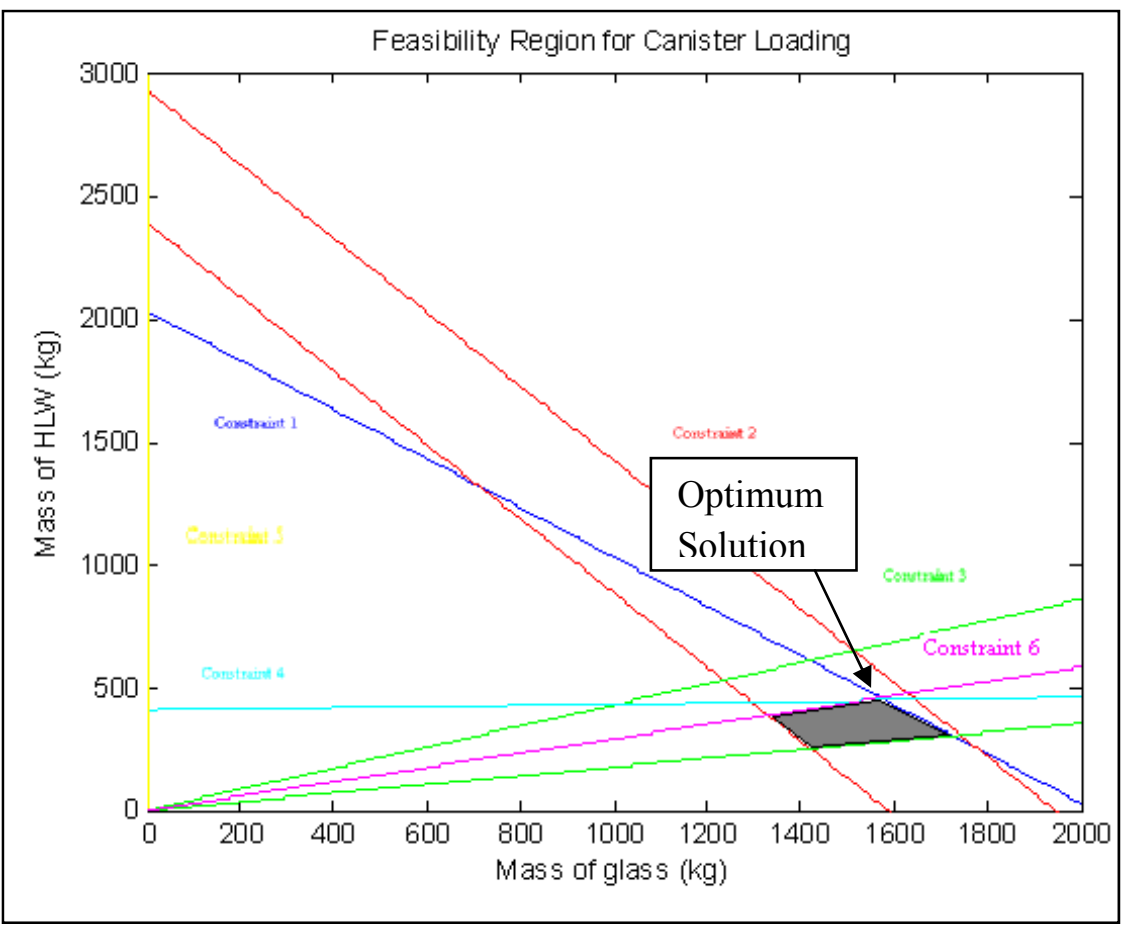

Figure 28: Feasibility Solution for BU $=80 \%$ FIMA and cooling of 20 years for LIFE fueled with used PWR fuel (PUREX used) 
Table 6: Key statistics for cask loading. The optimal solution of mass of HLW and glass in the container are give, as well as the number of canisters required for loading, normalized per tHM and per GWd. Cooling times were five or ten years before solidification.
Fuel Type

\section{FIMA (\%)}
PUREX?
Mass of HLW (per canister) (kg)
Mass of glass (per canister) (kg)
Number of (per tHM)
Number of canisters (per GWd) canisters

(

\begin{tabular}{|c|c|c|c|c|c|c|}
\hline LIFE (used PWR fuel) & No & 30.510 & 435.0 & 1598.5 & 3.13 & $1.06 \mathrm{E}-02$ \\
\hline LIFE (used PWR fuel) & No & 50.147 & 265.5 & 1504.5 & 5.70 & $1.16 \mathrm{E}-02$ \\
\hline LIFE (used PWR fuel) & No & 60.265 & 254.5 & 1439.5 & 5.98 & $1.02 \mathrm{E}-02$ \\
\hline LIFE (used PWR fuel) & No & 70.528 & 249.0 & 1412.0 & 6.12 & 8.90E-03 \\
\hline LIFE (used PWR fuel) & No & 80.196 & 252.0 & 1429.0 & 6.08 & 7.77E-03 \\
\hline LIFE (used PWR fuel) & No & 90.045 & 343.0 & 1690.0 & 4.48 & $5.10 \mathrm{E}-03$ \\
\hline LIFE (used PWR fuel) & No & 99.441 & 506.0 & 1527.0 & 3.04 & $3.13 \mathrm{E}-03$ \\
\hline $\begin{array}{l}\text { LIFE (used PWR } \\
\text { fuel)* }\end{array}$ & Yes & 30.510 & 268.5 & 1524.5 & 2.33 & $7.86 \mathrm{E}-03$ \\
\hline $\begin{array}{l}\text { LIFE (used PWR } \\
\text { fuel)* }\end{array}$ & Yes & 50.147 & 259.5 & 1471.5 & 3.48 & 7.08E-03 \\
\hline LIFE (used PWR fuel) & Yes & 60.265 & 260.5 & 1475.5 & 3.84 & $6.54 \mathrm{E}-03$ \\
\hline $\begin{array}{l}\text { LIFE (used PWR } \\
\text { fuel)* }\end{array}$ & Yes & 70.528 & 266.5 & 1507.5 & 4.13 & $6.00 \mathrm{E}-03$ \\
\hline $\begin{array}{l}\text { LIFE (used PWR fuel) } \\
*\end{array}$ & Yes & 80.196 & 280.5 & 1591.0 & 4.23 & $5.41 \mathrm{E}-03$ \\
\hline LIFE (used PWR fuel) & Yes & 90.045 & 276.5 & 1568.5 & 4.60 & $5.23 \mathrm{E}-03$ \\
\hline LIFE (used PWR fuel) & Yes & 99.441 & 443.0 & 1590.0 & 3.04 & $3.13 \mathrm{E}-03$ \\
\hline LIFE (thorium) & No & 30.013 & 610.0 & 1423.0 & 2.52 & $8.80 \mathrm{E}-03$ \\
\hline LIFE (thorium) & No & 50.138 & 501.0 & 1532.5 & 3.11 & $6.50 \mathrm{E}-03$ \\
\hline LIFE (thorium) & No & 60.130 & 491.5 & 1542.5 & 3.20 & $5.56 \mathrm{E}-03$ \\
\hline LIFE (thorium) & No & 70.059 & 508.5 & 1525.5 & 3.12 & $4.63 \mathrm{E}-03$ \\
\hline LIFE (thorium) & No & 80.036 & 538.0 & 1495.0 & 2.96 & $3.84 \mathrm{E}-03$ \\
\hline LIFE (thorium) & No & 90.007 & 566.5 & 1476.5 & 2.83 & $3.27 \mathrm{E}-03$ \\
\hline LIFE (thorium) & No & 94.177 & 546.0 & 1487.0 & 2.93 & $3.25 \mathrm{E}-03$ \\
\hline LIFE (thorium) & Yes & 30.013 & 333.0 & 1701.0 & 2.04 & $7.13 \mathrm{E}-03$ \\
\hline LIFE (thorium) & Yes & 50.138 & 318.0 & 1715.0 & 2.77 & $5.79 \mathrm{E}-03$ \\
\hline LIFE (thorium) & Yes & 60.130 & 337.5 & 1696.0 & 2.90 & $5.06 \mathrm{E}-03$ \\
\hline LIFE (thorium) & Yes & 70.059 & 369.5 & 1345.0 & 2.92 & 4.34E-03 \\
\hline LIFE (thorium) & Yes & 80.036 & 445.0 & 1588.0 & 2.64 & $3.45 \mathrm{E}-03$ \\
\hline LIFE (thorium) & Yes & 90.007 & 452.5 & 1580.5 & 2.82 & $3.27 \mathrm{E}-03$ \\
\hline LIFE (thorium) & Yes & 94.177 & 450.0 & 1583.0 & 2.93 & $3.25 \mathrm{E}-03$ \\
\hline PWR (5.0 wt \%) & Yes & $50 \mathrm{GWd} / \mathrm{tHM}$ & 546 & 1487 & 0.188 & 0.00375 \\
\hline
\end{tabular}

\footnotetext{
* Cooling time was ten years because no solution existed for five years cooling - decay heat constraint.
} 


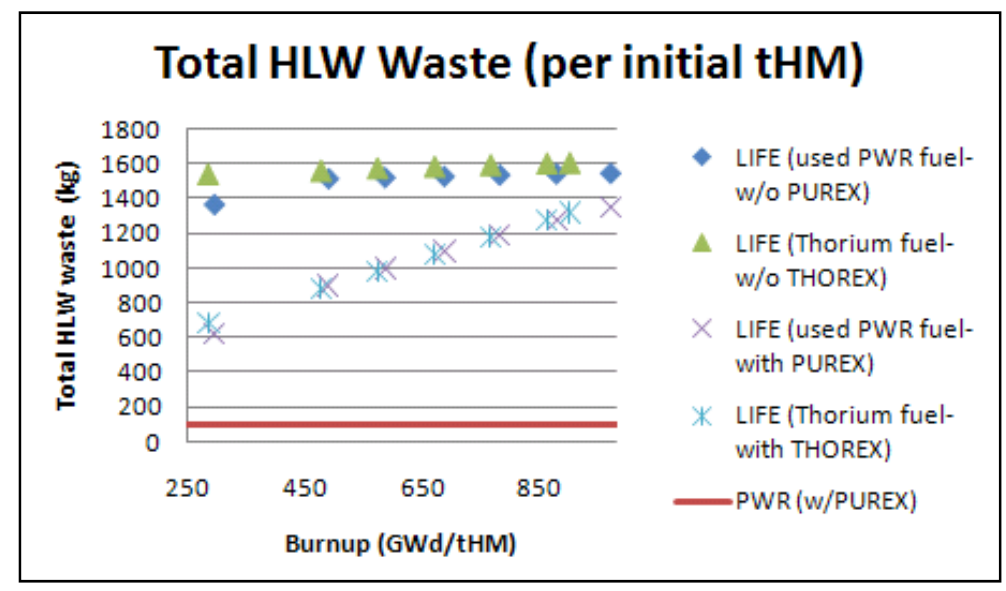

Figure 29: Total HLW waste generated per initial tHM (decay time of five years)

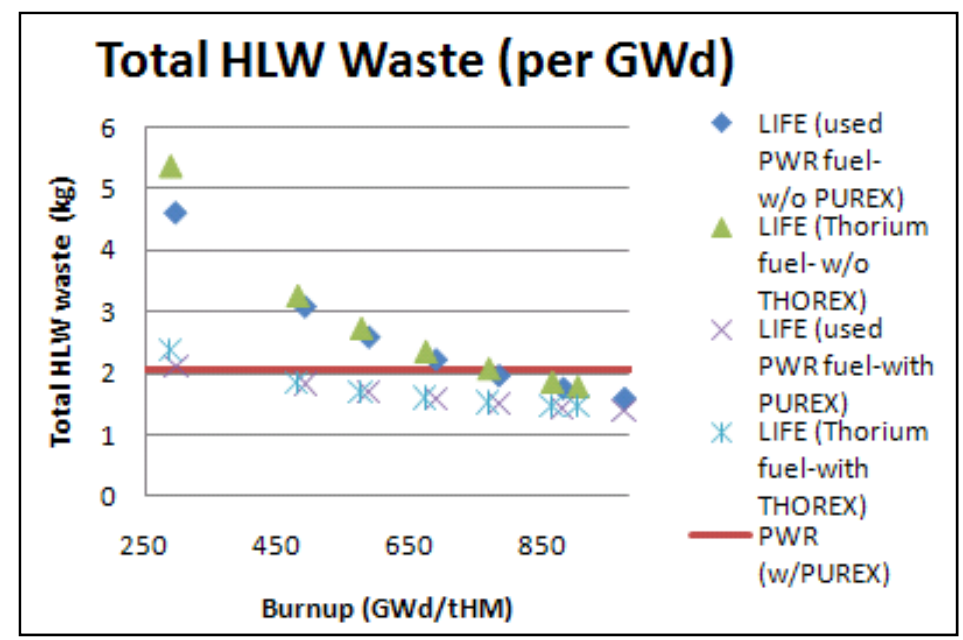

Figure 30: Total HLW generated per GWd (decay time of five years)

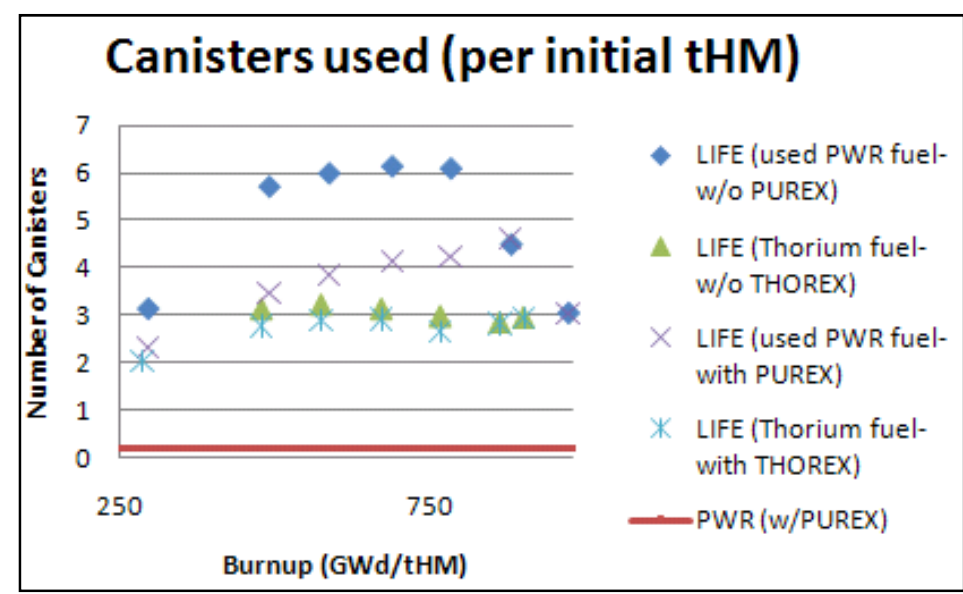

Figure 31: Fraction of canister needed to store HLW per initial tHM (decay time of five years) 


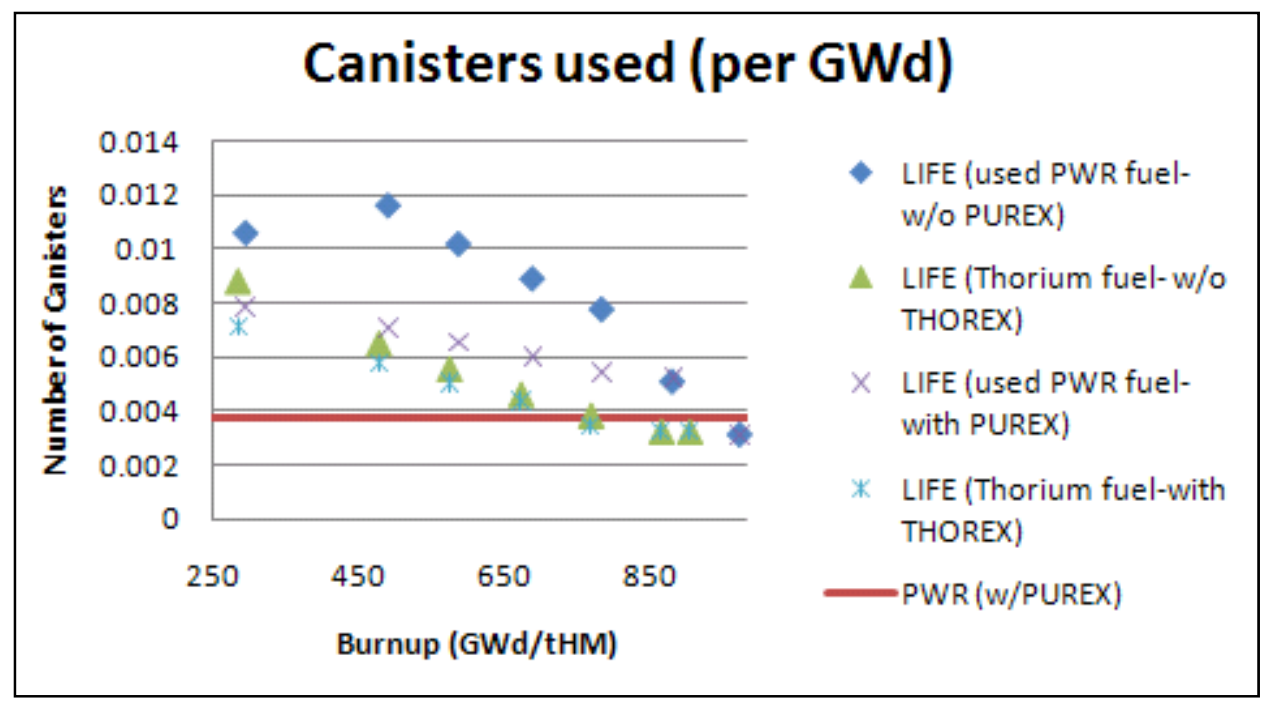

Figure 32: Fraction of canister needed to store HLW from a GWd (decay time of five years)

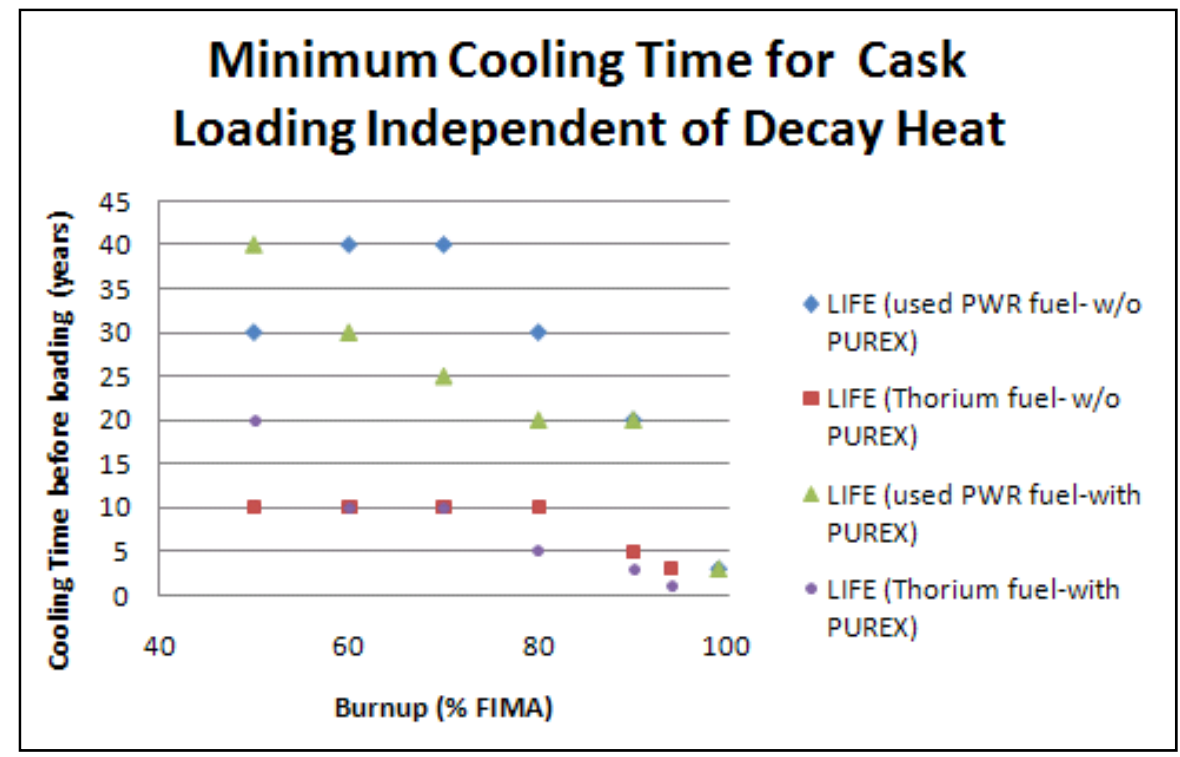

Figure 33: Minimum cooling time required for cask loading independent of decay heat 
Table 7: Key statistics for cask loading with optimized cooling times. The optimal solution of mass of HLW and glass in the container are give, as well as the number of canisters required for loading, normalized per tHM and per GWd.

\begin{tabular}{|c|c|c|c|c|c|c|}
\hline Fuel Type & PUREX? & FIMA (\%) & $\begin{array}{l}\text { Mass of } \\
\text { HLW (per } \\
\text { canister) } \\
(\mathrm{kg})\end{array}$ & $\begin{array}{l}\text { Mass of } \\
\text { glass (per } \\
\text { canister) } \\
(\mathrm{kg})\end{array}$ & $\begin{array}{l}\text { Number of } \\
\text { canisters } \\
\text { (per initial } \\
\text { tHM) }\end{array}$ & $\begin{array}{l}\text { Number of } \\
\text { canisters } \\
\text { (per GWd) }\end{array}$ \\
\hline LIFE (used PWR fuel) & No & 30.510 & 610.0 & 1423 & 2.23 & 0.00755 \\
\hline LIFE (used PWR fuel) & No & 50.147 & 610.0 & 1423.0 & 2.48 & 0.00504 \\
\hline LIFE (used PWR fuel) & No & 60.265 & 610.0 & 1423.0 & 2.49 & 0.00424 \\
\hline LIFE (used PWR fuel) & No & 70.528 & 610.0 & 1423.0 & 2.50 & 0.00363 \\
\hline LIFE (used PWR fuel) & No & 80.196 & 592.5 & 1441.5 & 2.59 & 0.00331 \\
\hline${ }_{*}^{\text {LIFE (used PWR fuel) }}$ & No & 90.045 & 539.5 & 1494.5 & 2.86 & 0.00325 \\
\hline${ }_{*}^{2}$ LIFE (used PWR fuel) & No & 99.441 & 506.0 & 1527.0 & 3.04 & 0.00313 \\
\hline LIFE (used PWR fuel) & Yes & 30.510 & 558.5 & 1474.5 & 1.13 & 0.00383 \\
\hline LIFE (used PWR fuel) & Yes & 50.147 & 527.0 & 1506.0 & 1.73 & 0.00352 \\
\hline * LIFE (used PWR fuel) & Yes & 60.265 & 521.0 & 1512.0 & 1.93 & 0.00328 \\
\hline LIFE (used PWR fuel) & Yes & 70.528 & 476.0 & 1557.0 & 2.31 & 0.00336 \\
\hline LIFE (used PWR fuel) & Yes & 80.196 & 459.5 & 1574.5 & 2.59 & 0.00331 \\
\hline * LIFE (used PWR fuel) & Yes & 90.045 & 445.5 & 1587.5 & 2.86 & 0.00325 \\
\hline${ }_{*}^{2}$ LIFE (used PWR fuel) & Yes & 99.441 & 443.0 & 1590.0 & 3.04 & 0.00313 \\
\hline LIFE (thorium) & No & 30.013 & 610.0 & 1423 & 2.55 & 0.00534 \\
\hline LIFE (thorium) & No & 50.138 & 610.0 & 1423 & 2.57 & 0.00447 \\
\hline LIFE (thorium) & No & 60.130 & 610.0 & 1423.0 & 2.58 & 0.00447 \\
\hline LIFE (thorium) & No & 70.059 & 610.0 & 1423.0 & 2.59 & 0.00385 \\
\hline LIFE (thorium) & No & 80.036 & 610.0 & 1423.0 & 2.61 & 0.00339 \\
\hline LIFE (thorium) ${ }^{*}$ & No & 90.007 & 565.5 & 1467.5 & 2.83 & 0.00327 \\
\hline LIFE (thorium) & No & 94.177 & 546.0 & 1487.0 & 2.93 & 0.00325 \\
\hline LIFE (thorium) ${ }^{*}$ & Yes & 30.013 & 610.0 & 1423.0 & 1.12 & 0.00390 \\
\hline LIFE (thorium) ${ }^{*}$ & Yes & 50.138 & 552.5 & 1480.5 & 1.60 & 0.00334 \\
\hline LIFE (thorium) $^{*}$ & Yes & 60.130 & 512.5 & 1520.5 & 1.91 & 0.00333 \\
\hline LIFE (thorium) ${ }^{*}$ & Yes & 70.059 & 484.5 & 1548.5 & 2.23 & 0.00331 \\
\hline LIFE (thorium) $^{*}$ & Yes & 80.036 & 465.5 & 1567.5 & 2.53 & 0.00330 \\
\hline LIFE (thorium) ${ }^{*}$ & Yes & 90.007 & 452.5 & 1580.5 & 2.82 & 0.00327 \\
\hline LIFE (thorium) $^{*}$ & Yes & 94.177 & 450.0 & 1583.0 & 2.93 & 0.00325 \\
\hline
\end{tabular}

\footnotetext{
* Constrained by $\mathrm{MoO}_{3}$ content
} 


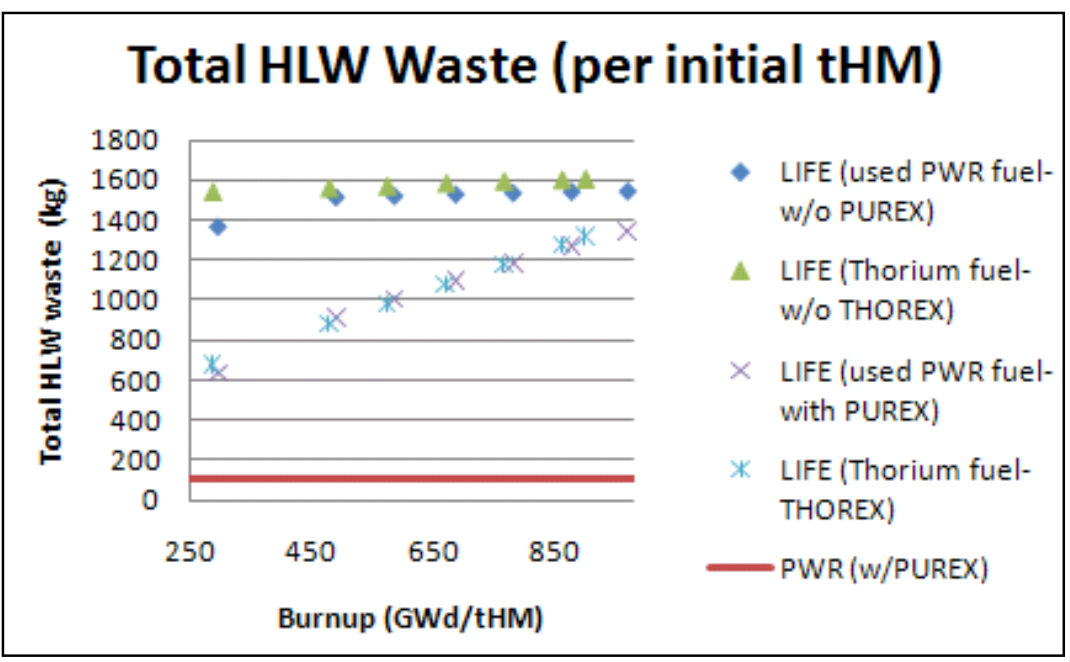

Figure 34: Total HLW waste for optimized cooling times

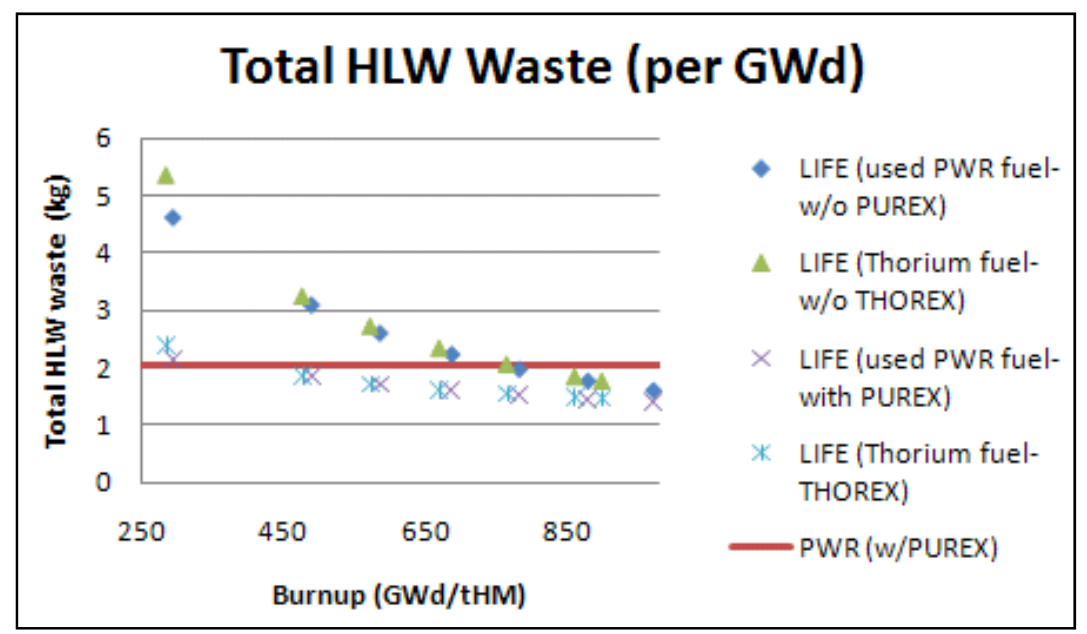

Figure 35: Total HLW (per GWd) for optimized cooling time

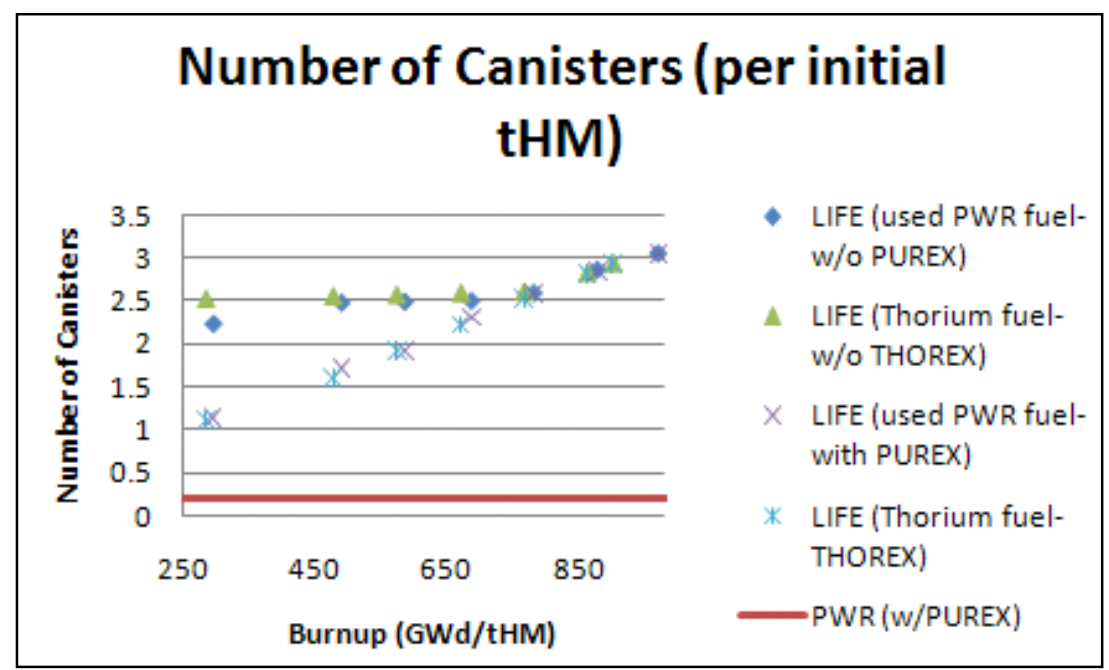

Figure 36: Number of canisters (per tHM) for optimized cooling time 


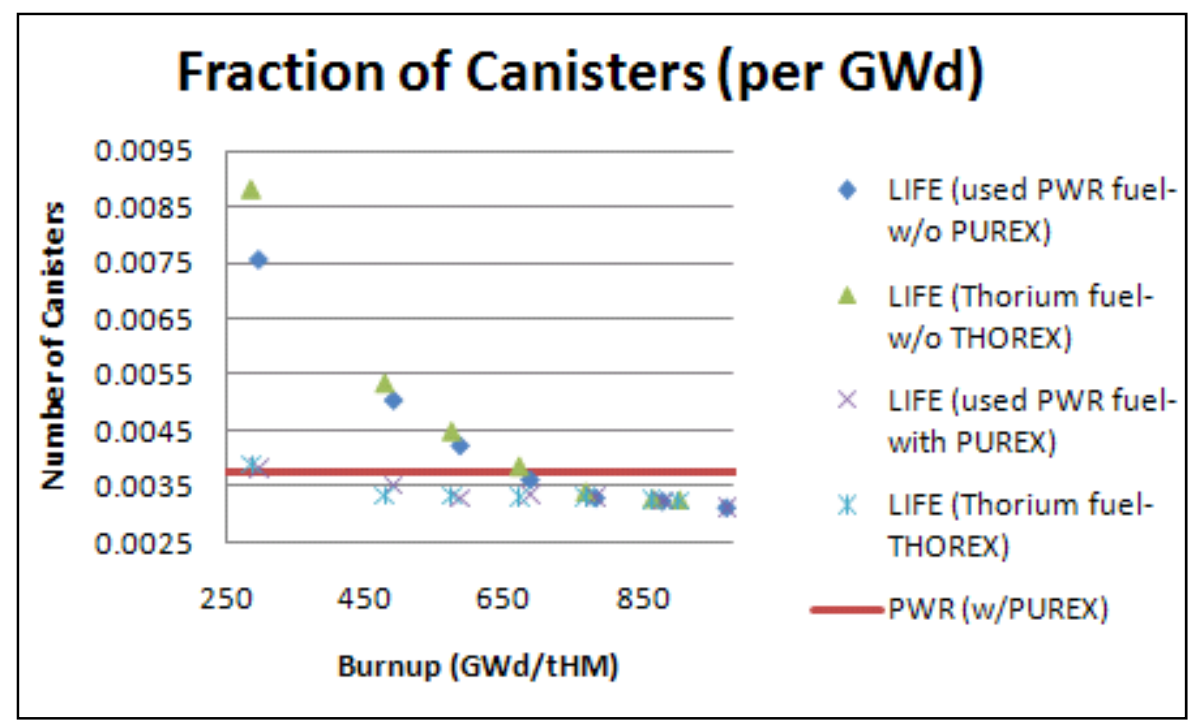

Figure 37: Number of canisters (per GWd) for optimized cooling time

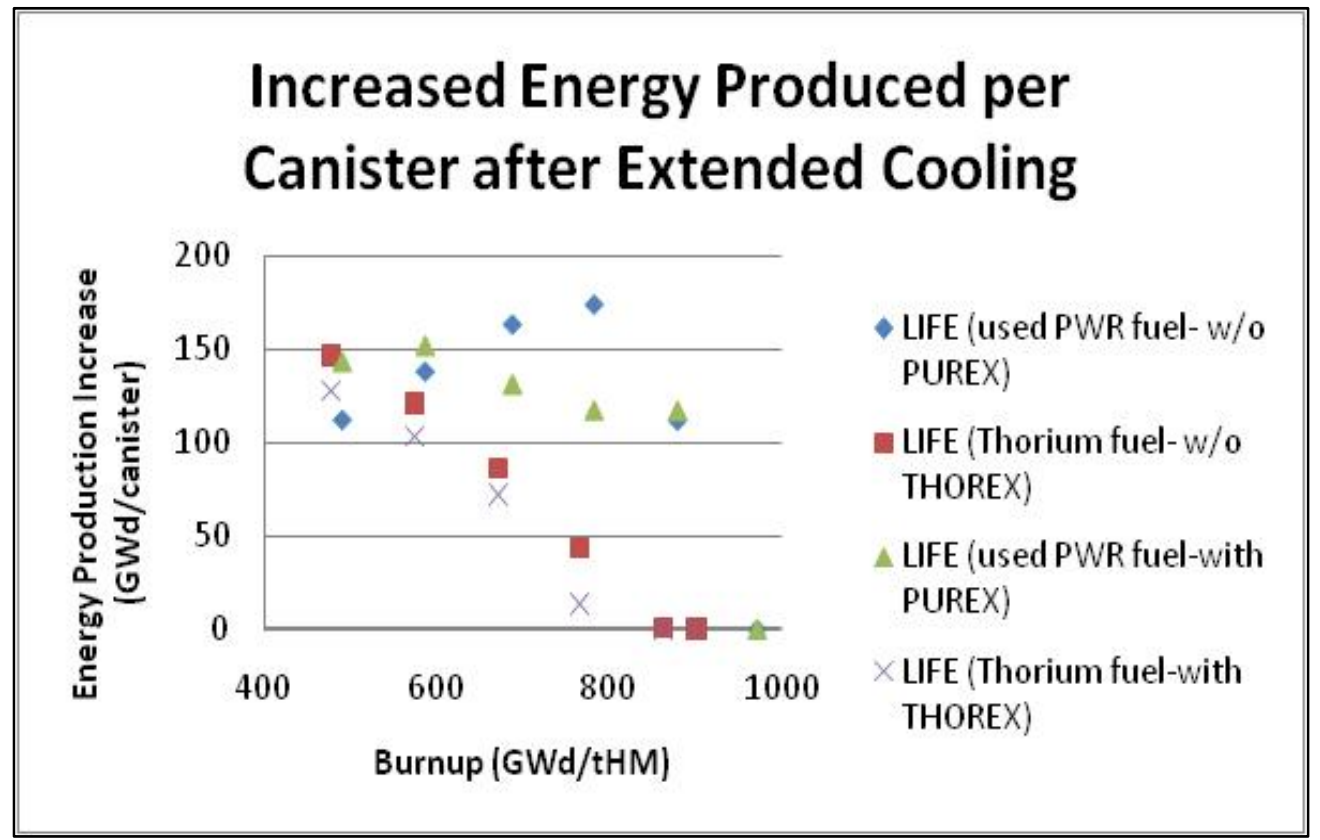

Figure 38: Increased energy production per canister after optimized cooling time 
Table 8: Energy content per canister

\section{LIFE (used PWR fuel)}

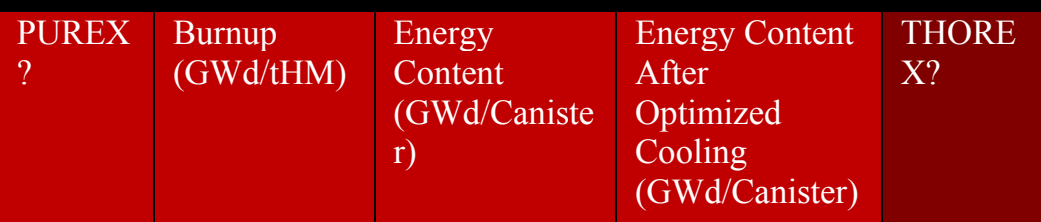

\section{LIFE (thorium fuel)}

\begin{tabular}{|l|l|l|} 
Burnup & Energy & Energy Content \\
$($ GWd/tHM & Content & After \\
) & $(G W d / C a n i s t e$ & Optimized \\
& r) & Cooling \\
& & $($ GWd/Canister
\end{tabular}

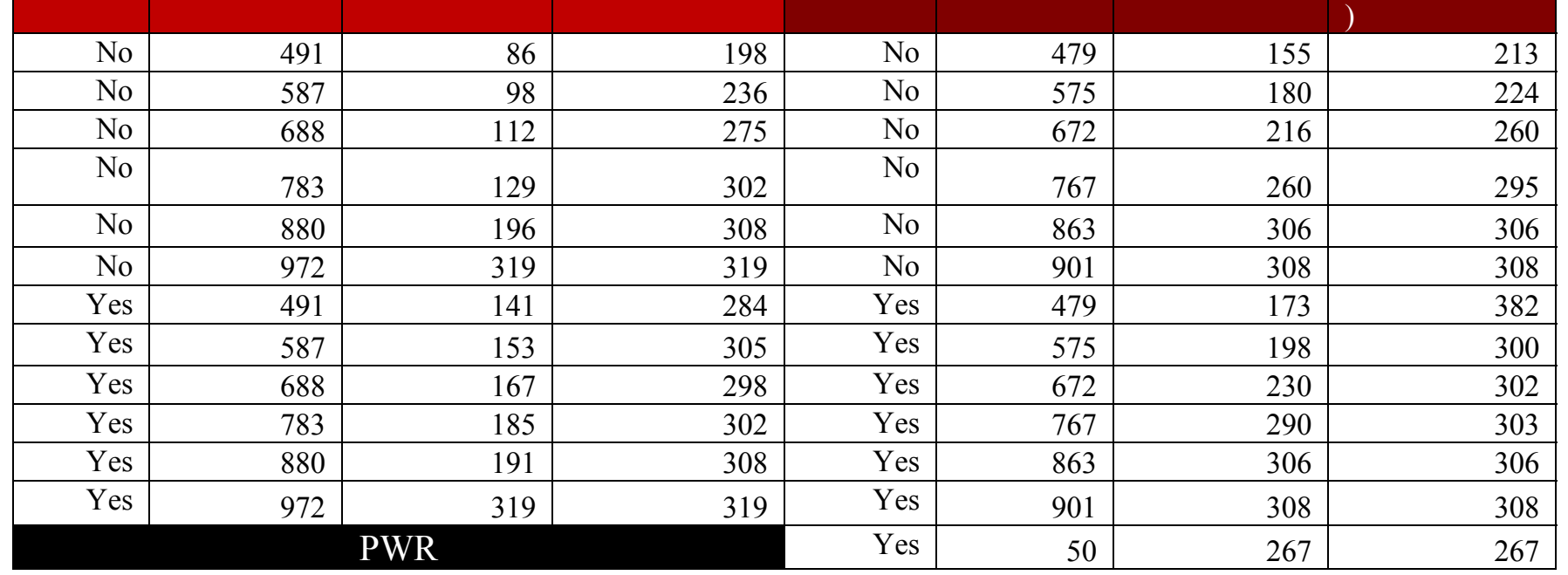




\section{CONCLUSIONS:}

This study determined the repository performance of spent nuclear fuel from LIFE and compared to that of discharged fuel from LWR. For LIFE two fuel options were considered: (1) used fuel from LWR recovered through a dry process (AIROX); (2) thorium. The burnup level was varied between $25 \%$ and 99\% FIMA for LIFE systems, while it was fixed at $~ 5 \%$ FIMA $(50 \mathrm{GWd} / \mathrm{tHM})$ for LWR. It was assumed that the HLW arising from each fuel cycle is conditioned and vitrified before disposal. Conditioning might or might not be preceded by PUREX or THOREX reprocessing.

The repository performance was expressed in number of canisters required to store HLW from the production of one unit energy $(1 \mathrm{kWh})$. The maximum possible HLW waste load per canister was determined using linear programming techniques that allowed combination of canister design and regulatory constraints. In order to reduce the number of required canisters, spent fuel was allowed to cool long enough that decay heat was not a constraint. It was found that 40 years or less serve to the purpose.

It was found that LIFE, besides increasing resource utilizations, reduces repository space requirements, compared to LWR, when burnup reaches beyond 70\% FIMA, even if no reprocessing is applied. Assuming burnup of 50\% FIMA, if PUREX reprocessing is applied, LIFE spent fuel requires a maximum of $1.47 \mathrm{E}-10$ canisters starting from used fuel and 1.39E-10 canisters from thorium per $\mathrm{kWh}(0.147$ and $0.139 \mathrm{TWh}$ per canister, respectively). A LWR requires $1.56 \mathrm{E}-10$ canisters per $\mathrm{kWh}(0.156 \mathrm{TWh}$ per canister). The required number of canisters decreases with fuel burnup. If uranium and plutonium are not separated from LIFE spent fuel then a maximum of 2.10E-10 canisters are required in the used fuel case and 1.96E-10 canisters in the thorium case per $\mathrm{kWh}(0.210$ and $0.196 \mathrm{TWh}$ per canister, respectively).

The smallest optimal solution values for HLW per canister were from the LIFE system fueled with AIROX reprocessed fuel. It benefited the greatest from the increased cooling time. An exception to this is at very high burnups of $99.417 \%$ FIMA, where the heat content was very low. Thorium fuel performed better for shorter cooling time, and both LIFE fuels behaved comparably when allowed to cool for long periods of time before solidification. Reprocessed fuels tended to perform better than non reprocessed fuels.

This study also determined the main properties (activity levels, decay heat, radiotoxicity, neptunium-237 and precursor levels, total neutron source levels, product mass, TRU mass, fissile mass, fissile fraction, and fissile plutonium fraction) of the spent fuel from each cycle as a function of time after discharge. Of particular importance to repository performance are radiotoxicity and neptunium-237 and precursor levels. Ingestion levels tended to be higher for LIFE, unless high burnups are reached. Neptunium-237 and precursor levels were higher for LIFE fueled with used LWR fuel, but much lower for LIFE fueled with thorium. Low radiotoxicity and neptunium-237 and precursor levels would reduce environmental impact. For these properties, rankings were made qualitatively based on the graphed results; the average performance for all burnups was realized. Some burnups had better or worse performance with regard to specific parameters. Further work could involve weighting certain parameters as more important than others. For instance, radiotoxicity may have more impact than fissile fraction in decision-making. Also, a method for more qualitatively ranking the data could be implemented.

However, a major exception to the general rules is the behavior of the used PWR fuel for LIFE at very high burnup. This, along with the thorium fuel at high burnup, minimized almost every category most effectively, for both normalizations. Given that the casks loaded with the 
highest burnup fuel have the maximum energy content, the very high burnups offer significant repository benefits over lower burnup and used PWR fuel.

Several limitations for both components of the study should be noted. For the cask loading optimization, LIFE spent fuel is unlikely to be reprocessed using the PUREX method, as there is already high burnup from LIFE. However, some processing is necessary and the assumption of PUREX allows for a better comparison, and allows for calculation of glass frit mass needed. Additionally, it was assumed that the amount of process and corrosion chemicals required was linear proportional to the mass of HLW. Finally, heavy metals were extracted via the PUREX process for the commercial used fuel that was not also extracted for the LIFE system. Those heavy metals would still need to be disposed of in some form, even if they were refabricated into fuel and reused. Extraction was not modeled in the property comparison part of the study. 


\section{Works Cited}

Ahn, J., \& Choen, M. (2006). Linear Programming Appproach for Optimization of Radionuclide Loading in Vitrified HLW. Nuclear Technology, 303-319.

Fratoni, M. (2010, May). Outputs from TAPE7 for used LWR LIFE fuel. Email Coorespondence . Lawrence Livermore National Laboratory.

Gauld, I. e. (2009, January). ORIGEN-S: SCALE SYSTEM MODULE TO CALCULATE FUEL DEPLETION, ACTINIDE TRANSMUTATION, FISSION PRODUCT BUILDUP AND DECAY, AND ASSOCIATED RADIATION SOURCE TERMS. Oak Ridge National Laboratory.

Powers, J. (2010, June). Outputs from TAPE7 for LIFE fueled with thorium. Email Coorespondence . Lawrence Livermore National Laboratory.

Saling, J., \& Fentiman, A. (2001). Radioactive Waste Management. New York: Taylor \& Francis. 


\section{APPENDIX}

\section{Matlab Script for Linear Programming}

\section{LPsolution.m}

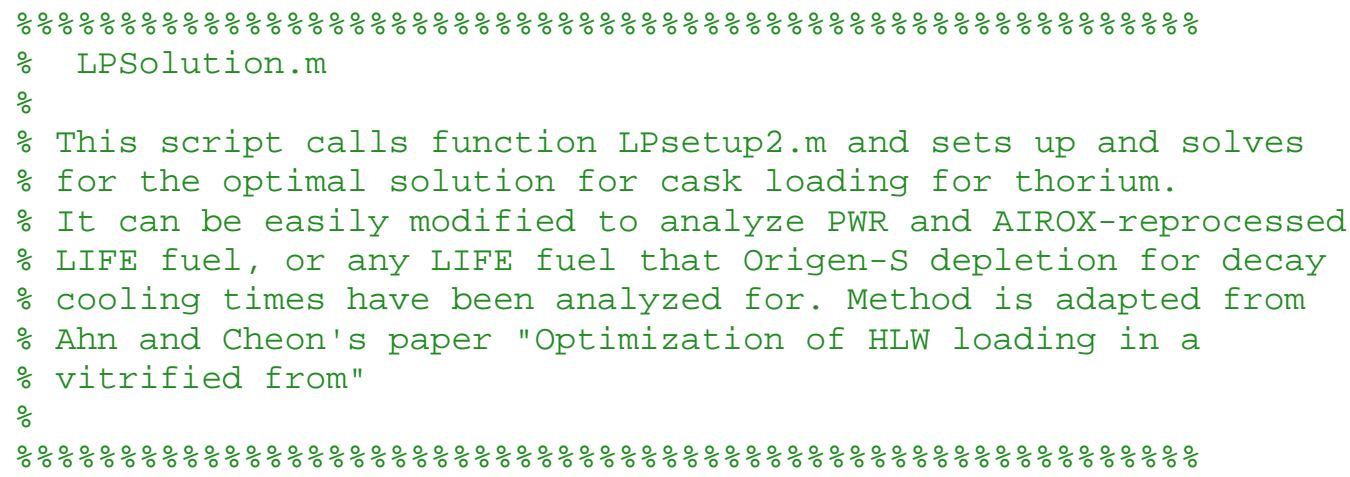


[zeta xWPU XMo03 xWNa20 xGNa20 TotalHLW coolingtime] = LPsetup2(input1);

$\%$ calls function to calculate parameters

$\mathrm{Vc}=.823 ; \%$ volume of canister in $\mathrm{m} 3$

$\operatorname{maxPu}=2.5 ; \% \max$ plutonium content

MG $=0: .5: 2000 ; \%$ used to graph constraints- mass of glass

zetamatrix = xlsread('LibrariesforLP.Xls', 'zeta'); \% calls library

containing interpolation values

figure $(n)$

constraint1 = 2033-MG;

plot(MG, constraint1) \%constraint 1

title('Feasibility Region for Canister Loading') \%plots figure

xlabel('Mass of glass $(\mathrm{kg})$ ')

ylabel('Mass of HLW $\left.(\mathrm{kg})^{\prime}\right)$

axis ( [ $\left.\left[\begin{array}{llll}0 & 2000 & \odot & 3000\end{array}\right]\right)$

hold on

constraint2 $=2393.7-1.505 *$ MG; \%calculates constraint 2

plot(MG, constraint2, ' $r$ ') \%constraint 2

fplot('2932.3-1.505* $x^{\prime}$, [๑ 2000], ' $r$ ') \%constraint 2

fplot ('.1765* $\left.x^{\prime},[02000],{ }^{\circ} g^{\prime}\right) \%$ constraint 3

constraint $3=.4286^{*} \mathrm{MG}$;

plot(MG, constraint3, 'g') \%constraint 3

\%Calculating constraint 4 from Zeta (via interplation)

if zeta < zetamatrix $(1,1)$

fprintf('It is defintely not a constraint! You win! \n')

$\mathrm{K} 1=-1 ;$

$\mathrm{K} 2=-1 ;$

elseif zeta $<$ zetamatrix $(2,1)$

$\mathrm{K} 1=($ zeta - zetamatrix $(1,1)) /($ zetamatrix $(2,1)-$

zetamatrix $(1,1))$ * (zetamatrix $(2,2)$-zetamatrix $(1,2))+$ zetamatrix $(1,2)$;

$\mathrm{K} 2=($ zeta - zetamatrix $(1,1)) /($ zetamatrix $(2,1)-$

zetamatrix $(1,1))$ * (zetamatrix $(2,3)$-zetamatrix(1,3))+zetamatrix(1,3);

elseif zeta < zetamatrix $(3,1)$

$\mathrm{K} 1=($ zeta - zetamatrix $(2,1)) /($ zetamatrix $(3,1)-$

zetamatrix $(2,1)) *($ zetamatrix $(3,2)$-zetamatrix $(2,2))+$ zetamatrix $(2,2)$; $\mathrm{K} 2=($ zeta - zetamatrix $(2,1)) /($ zetamatrix $(3,1)-$

zetamatrix $(2,1))$ * (zetamatrix $(3,3)$-zetamatrix $(2,3))+$ zetamatrix $(2,3)$; elseif zeta < zetamatrix $(4,1)$

$\mathrm{K} 1=($ zeta - zetamatrix $(3,1)) /($ zetamatrix $(4,1)-$

zetamatrix $(3,1))$ * (zetamatrix $(4,2)$-zetamatrix $(3,2))+$ zetamatrix $(3,2)$; $\mathrm{K} 2=($ zeta - zetamatrix $(3,1)) /($ zetamatrix $(4,1)-$

zetamatrix $(3,1))$ * (zetamatrix $(4,3)$-zetamatrix $(3,3))+$ zetamatrix $(3,3)$; elseif zeta < zetamatrix $(5,1)$

$\mathrm{K} 1=($ zeta - zetamatrix $(4,1)) /($ zetamatrix $(5,1)-$

zetamatrix $(4,1))$ * (zetamatrix $(5,2)$-zetamatrix $(4,2))$ +zetamatrix $(4,2)$; $\mathrm{K} 2=($ zeta - zetamatrix $(4,1)) /($ zetamatrix $(5,1)$ -

zetamatrix $(4,1))$ * (zetamatrix $(5,3)$-zetamatrix $(4,3))+$ zetamatrix $(4,3)$; elseif zeta < zetamatrix $(6,1)$

$\mathrm{K} 1=($ zeta - zetamatrix $(5,1)) /($ zetamatrix $(6,1)-$

zetamatrix $(5,1))$ * (zetamatrix $(6,2)$-zetamatrix $(5,2))+$ zetamatrix $(5,2)$;

$\mathrm{K} 2=($ zeta - zetamatrix $(5,1)) /($ zetamatrix $(6,1)-$

zetamatrix $(5,1))$ * (zetamatrix $(6,3)$-zetamatrix $(5,3))+$ zetamatrix $(5,3)$;

elseif zeta < zetamatrix $(7,1)$

$\mathrm{K} 1=($ zeta - zetamatrix $(6,1)) /($ zetamatrix $(7,1)-$

zetamatrix $(6,1))$ * (zetamatrix $(7,2)$-zetamatrix $(6,2))$ +zetamatrix $(6,2)$;

$\mathrm{K} 2=($ zeta - zetamatrix $(6,1)) /($ zetamatrix $(7,1)$ -

zetamatrix $(6,1))$ * (zetamatrix $(7,3)$-zetamatrix $(6,3))$ +zetamatrix $(6,3)$; 
else

fprintf('Zeta is too high for a feasible solution to exist :( Try

letting it cool some more. Wah wah \n')

$\mathrm{K} 1=0 ;$

$\mathrm{K} 2=0 ;$

end

constraint4 $=M \mathrm{MG}^{*} \mathrm{~K} 1+\mathrm{K} 2 ; \% \mathrm{plots}$ constraint4 (heat)

plot (MG, constraint4, ' $\mathrm{C}$ ')

constraint5 $=$ maxPu*Vc/xWPU*MG; \%constraint 5(plutonium)

plot(MG, constraint5, ' $y$ ')

constraint6 $=\left(.02 /\left(\mathrm{XMOO3}_{-} .02\right)\right){ }^{*} \mathrm{MG} ; \%$ constraint 6 moly

plot(MG, constraint6, 'm')

constraint $7=(.1-x G N a 20) /(x W N a 20-.1) * M G ; \%$ constraint 7 sodium

plot (MG, constraint7, 'k')

hold off

$\% \%$ inds intersection point of optimal point

$\% \% * * * * * * *$ IMPORTANT********

$\%$ YOU ***MUST*** change the constraints to find the intersection

$\%$ based on the specific feasibility solution. This is NOT

$\%$ done automatically.

[row col] $=$ size $($ constraint 1$)$;

for $i=1: 1: \operatorname{col}$

if abs(constraint4(i) - constraint1(i)) $<.5$

MGlass = MG(i);

end

MWaste $=$ constraint $4(i)$;

end

Enormal $=($ BUlife * Mlife $) ;$ \%energy normalization

fprintf('Optimum loading of a canister \%.2d $\mathrm{kg}$ of $\mathrm{HLW}$ and \%.4d $\mathrm{kg}$ of glass $\backslash n '$, MWaste, MGlass)

NumCanisters $=[$ TotalHLW/MWaste TotalHLW/MWaste $(7.81 \mathrm{e} 4 / 1000) / 585$

(7.81e4/1000)/585]; \%per MTU for LIFE and PWR ref. Ahn

Wastegen $=[$ TotalHLW/Mlife TotalHLW/Enormal $(7.81 \mathrm{e} 4 / 1000)$

(7.81e4/1000)/28 BUlife];

NumCanistersn $=[$ NumCanisters(1)/Mlife NumCanisters(2)/Enormal

NumCanisters(3) NumCanisters(4)/28];

$\mathrm{n}=\mathrm{n}+1$

$i$ = input('Type 1 to continue the analysis for a different cooling

time \nType 2 to end process $\left.\backslash n^{\prime}\right)$;

output $=$ [Wastegen NumCanistersn MWaste MGlass]; \%useful variable that outputs normalized total waste generated and canisters required end 


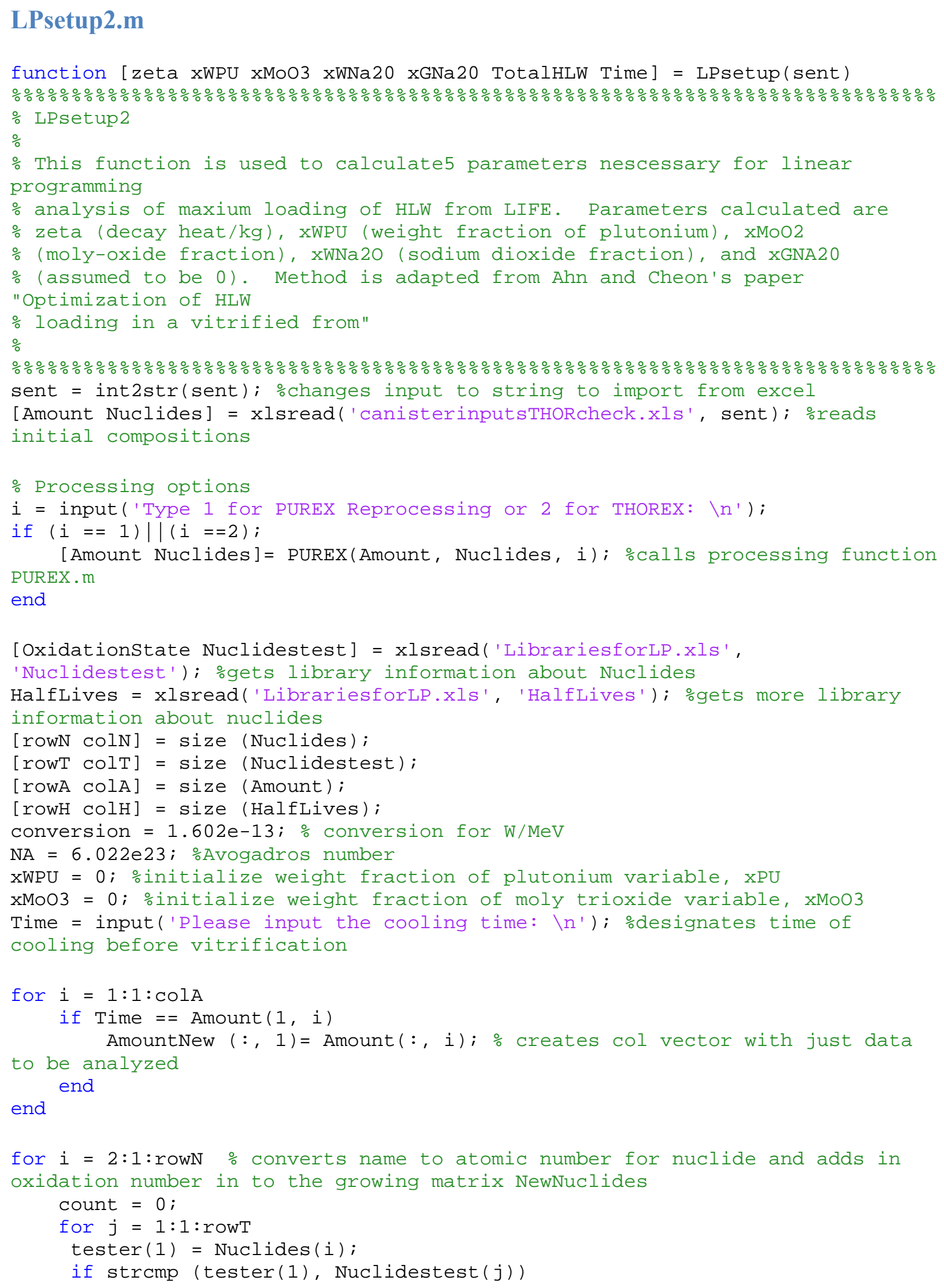




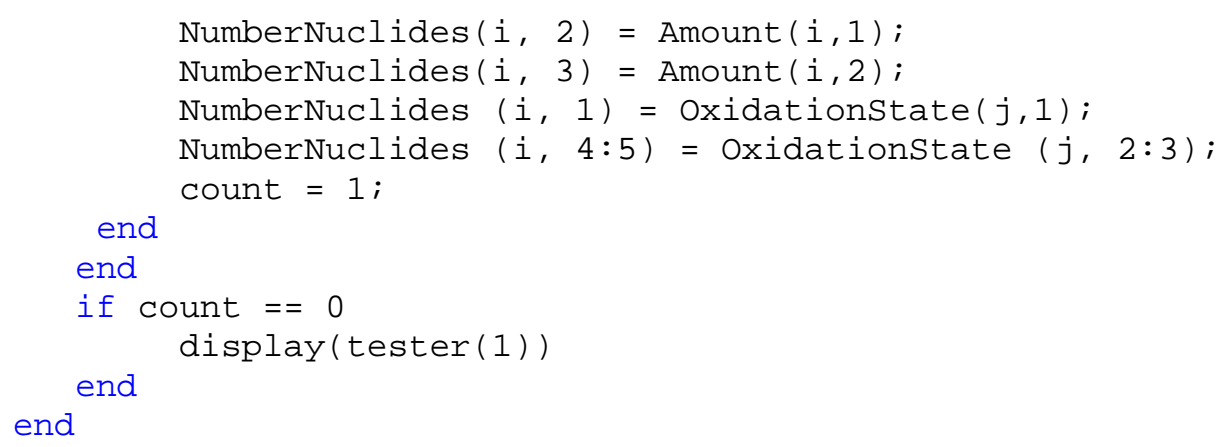




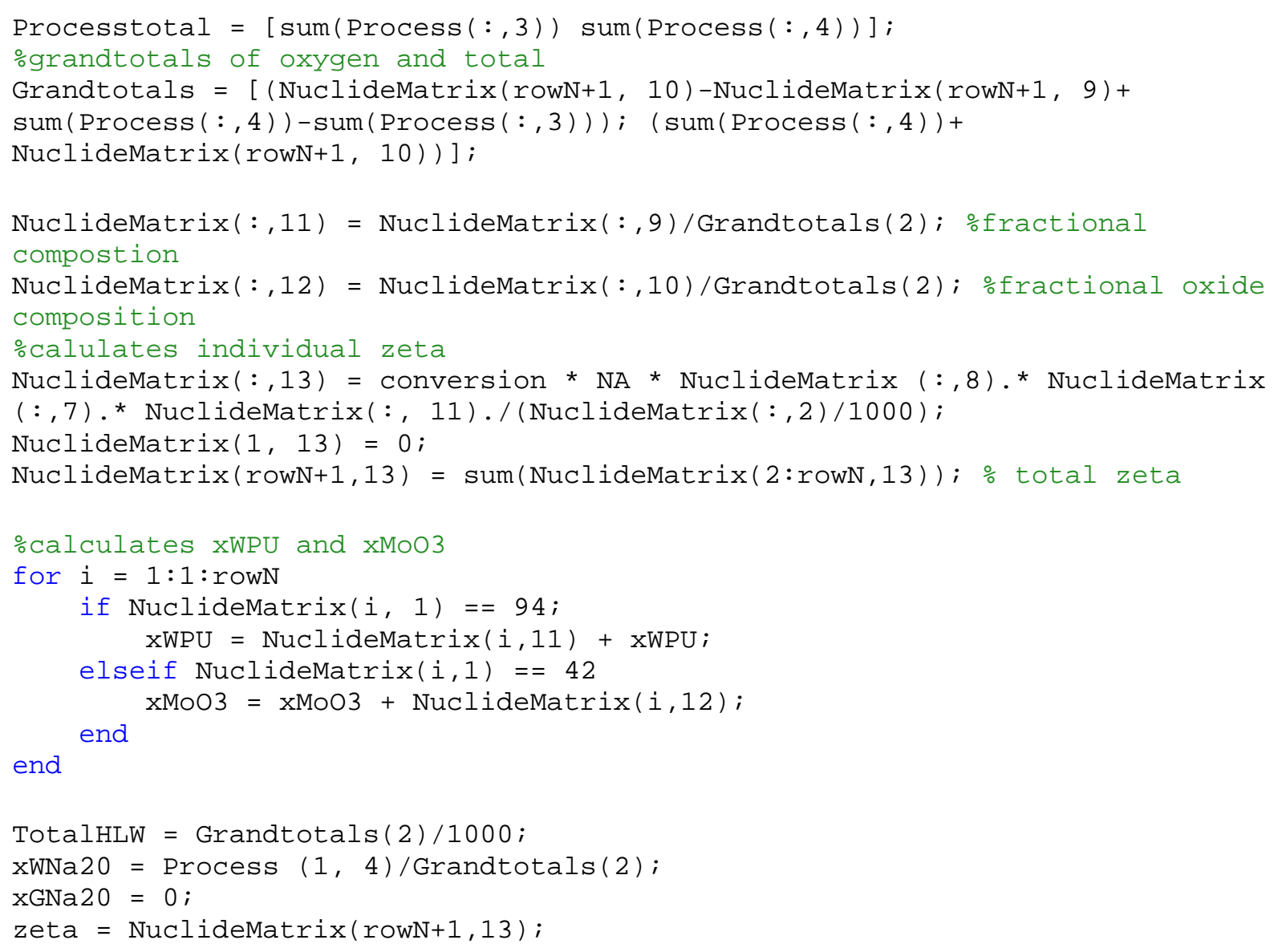




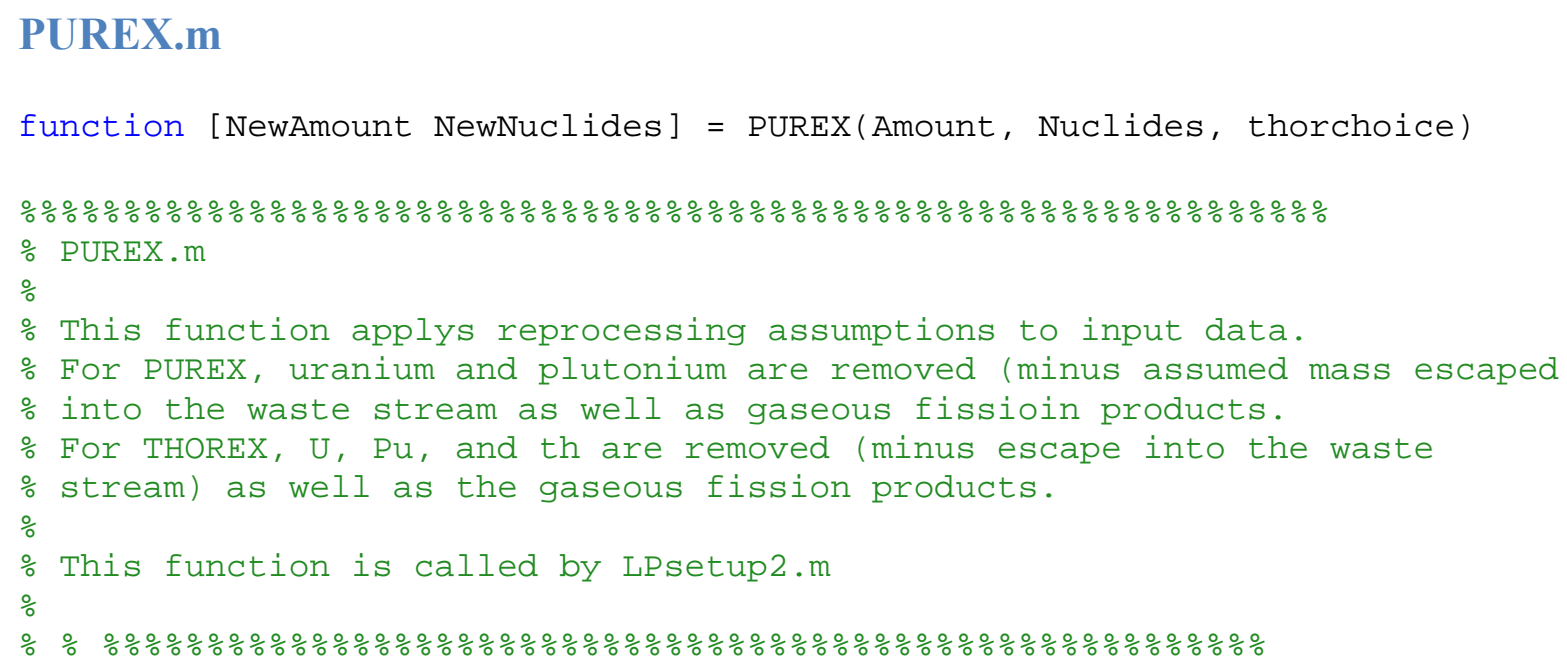




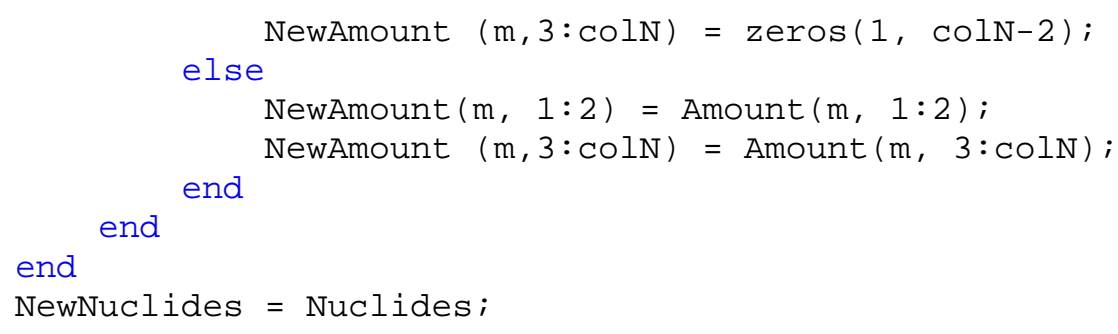

